\title{
The Proteids of Wheat.
}

\author{
BY \\ M. O'BRIEN, B.Sc., \\ Scholar of the 1851 Exhibition.
}

[The small reference figures throughout the Article refer to the numbers in the Bibliography given at the end.]

I.

TOWADAYS we are so accustomed to think of definite grains as the normal form of nitrogenous reserves in seeds, that we look on the occurrence of gluten in wheat as exceptional. Curiously enough, however, it seems to have been the first form investigated, so that we find physiological chemists at the beginning of this century trying to identify the nitrogenous organic substances of other seeds with the gluten of wheat. The same idea is embodied in the name Klebermehl, given by Hartig $\left(\mathrm{I} 855^{16 a}\right)$ to what are known as aleuron-grains, and in the term Aleuron itself which he introduced $\left(\mathrm{I} 85^{6} 6^{16 b}\right)$ for the nitrogenous crystalloid parts of these grains.

This however was nearly a hundred years after the death of Beccari ${ }^{1}$ ( 1766 ), who first investigated and isolated the tenacious substance to be obtained from wheat-flour by

- washing; and named it gluten. It probably soon attracted attention, but its characteristics cannot have been very fully studied last century, for we find Einhof stating in 1805 that chemists deny its solubility in alcohol. (Reference is given to Cadet $^{2}$ as one of these.)

[Annals of Botany, Vol. IX. No. XXXIV. June, I895.] 
Einhof's ${ }^{3}$ researches seem to have been chiefly concerned with rye and barley, among the cereals; but incidentally he describes some of the properties of the gluten of wheat. By washing rye-flour a tough gluten-like mass is at first obtained, but on continuing the washing this mass breaks down to a crumbly substance - a fact which he attributes to the sugar and Pflanzenschleim present. His results may be thus tabulated :-

N. matter soluble \{ coagulated on boiling (I) Pflanzeneiweiss.

in water $\{$ not coagulated

(2) Honey-like residue on evaporation.

The residue (2) may be resolved by treatment with alcohol into-
i. Kleber
Soluble in alcohol.
ii. Pflanzenschleim
Soluble only in water.

The 'Schleim' he seems to consider capable of being transformed into sugar ${ }^{3 b}$, and therefore of the nature of a gum or carbo-hydrate; it is, however, probably nitrogenous in character, giving a precipitate with tannic acid (cf. Ritthausen's Mucedin ; Einhof's Schleim, however, is precipitated by alcohol). The Kleber he identifies with the gluten of wheat, which, likewise, he describes as soluble in alcohol. Wheat-gluten, he says, though insoluble in the cold, dissolves on boiling with alcohol: whence we might conclude that it entirely did so, but for his statement that not so much of gluten dissolves when separated as is the case when it is still mixed with the other constituents of flour. His attempt to identify gluten with the albumin (Pfanzeneizeiss) is interesting, but it had to be abandoned because albumin is precipitated by alcohol, whilst gluten is to some extent soluble in it. Though his work is but little quoted, there is surely justice in his claim, ' $z u$ fernern Untersuchungen wenigstens die Bahn gebrochen zu haben.'

Tadde ${ }^{4}$ however is usually credited with having, in 1819 , first divided gluten into two substances by means of alcohol:

$$
\text { Gluten } \begin{cases}\text { soluble in boiling aicohol } & \text { gliadin. } \\ \text { residue, insoluble in alcohol } & \text { zymom. }\end{cases}
$$




\section{O'Brien.-The Proteids of Wheat.}

Gliadin is described as being partly deposited on cooling; as soluble in boiling water, to a frothy liquid; soluble in alkalies, only slightly soluble in acids, and insoluble in cold water. It forms a transparent, straw-yellow, sweetish mass, which on warming gives the smell of baked apples. (This I have not seen mentioned by any other writer, nor have I noticed it in the alcohol-extract from gluten. It is very marked, however, in a similar extract from bran-probably showing form-aldehyde. Nitric acid added to this solution is violently decomposed with evolution of red fumes.) The residue, $Z$ ymom, received its name ( $\zeta v_{\mu}^{\prime} \eta$, ferment) from its power of causing fermentation; it does not, however, itself ferment. It is soluble in acids, forms a kind of soap with alkalies, and is hardened by limewater and alkaline carbonates. It forms one-third of the volume of moist gluten, and is said to occur in many other vegetable bodies.

Though the name has not been adopted, I shall for the sake of clearness use the term $Z y m o m *$, as introduced by Taddei, to signify the part of gluten insoluble in boiling alcohol. Gliadin ( $\gamma$ ioía, glue) having been variously used by later writers, I shall employ the word Glian * for the whole of the alcohol-soluble part of gluten.

Berzelius ${ }^{6}$ carried the analysis by means of alcohol a step further, resolving glian into-

(I) Pflanzenleim soluble in cold as well as in hot alcohol [glutine*].

(2) Schleimige Stoffe precipitated from alcohol solution on cooling [myxon*].

For the former we may at once adopt the term proposed for it by De Saussure ${ }^{7}$ in 1833 , Glutine *. The latter substance appears later both as Fibrin and as Casein according to the theory of the writer: so for the sake of distinction we must find some name which commits us to neither view. I shall therefore designate as $M y x o n *$ ( $\mu \dot{v} \xi a$, slime) that part of gluten which is precipitated on cooling from solution in hot alcohol.

To these constituents of gluten a fourth was added by De Saussure 7 Mucine*. This name may be retained (as it 
has not been otherwise used with reference to plants) to denote that portion of the alcohol-soluble part of gluten (glian) which is soluble in cold water. As De Saussure was mainly concerned to find the constituent of gluten which effects the conversion of starch into sugar, and as he thought that mucine was the active substance, it was to this that he gave his chief attention, not distinguishing between glutine and myxon, as is shown in the following table-

Gluten $\begin{cases}\text { Insoluble in alcohol } & \text { Eiweiss [zymom]. } \\ \text { Soluble in alcohol, insoluble in water } & \text { Glutine [glutine and myxon]. } \\ \text { Soluble in alcohol and in water } & \text { Mucine. }\end{cases}$

From his omission of any distinct mention of what I have called myxon, later writers have identified his mucine with it: but as myxon represents about two-thirds of the dry weight of gluten, and mucine only $1 \%$, this is an impossible interpretation of his results.

Almost simultaneously with De Saussure's work, that of Payen and Persoz resulted in the discovery of diastase. Doubtless to the mixture of this ferment with gluten is due the action on starch which Kirchof ( 1813 ) attributed to gluten itself, De Saussure to mucine. A solution prepared as he prepared mucine, by constant reprecipitation by water of the glutine in the glian-extract, would contain diastase; but it is difficult to believe that it could retain its diastatic power if the first part of the preparation had been effected by boiling.

Boussingault ${ }^{8}$ in 1837 made a further step by the chemical analysis of crude gluten, of alcohol-soluble gluten (glian), and of pure gluten obtained by the solution of gluten in acetic acid and its precipitation by ammonium carbonate. He likewise noted that gluten does not constitute the whole of the nitrogenous matter of flour, extracting from the washings of gluten $1 \%$ of an albumin coagulating at $80^{\circ} \mathrm{C}$. [Cf. Einhof's Pflanzeneiweiss from rye ${ }^{3 a}$; and an albumin described by M. Henri in the washings of gluten, 1822.] The amount of nitrogen found in pure gluten was large, $18.9 \%$, agreeing closely with that in the albumin, $18.4 \%$.

Mulder ${ }^{9}$ likewise analysed both albumin and myxon from 
wheat. But his work is noteworthy rather for his elucidation of the similarity of animal and vegetable proteids than as regards our special subject. To him we owe not only the name 'proteid,' but also the xanthoproteic reaction.

Liebig ${ }^{11}$ and his school working at vegetable proteids gave considerable attention to the proteids of wheat, in which they distinguish an albumin and gluten. In the separation of gluten into its constituent parts Liebig does not proceed further than to zymom and glian (fibrin and Pfanzenleim); he does not consider it necessary to isolate mucine, for the two substances described agree so closely in chemical composition with crude gluten that the presence of a third, essentially different, substance is improbable.

Both albumin and Pflanzenleim (glian) are described by him as practically identical with egg-albumin; zymom only differs in its greater insolubility and is for the first time clearly identified with animal fibrin. Animal casein is not represented in wheat, but replaces gluten in leguminous and in oily seeds.

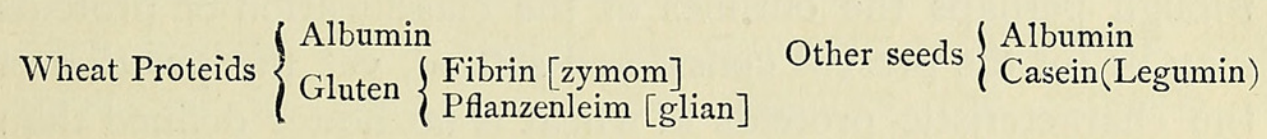

About the same time the French chemists, Dumas and Cahours ${ }^{13}$, were also working out the identity of animal and vegetable albuminous substances, and investigated the albumin and gluten of wheat very fully. They recognised in gluten the three constituents described by Berzelius; but the names they give indicate the more advanced, i. e. the comparative, stage which the inquiry had now reached.

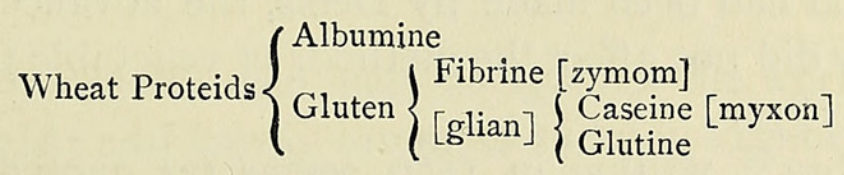

Zymom, they, too, describe as fibrin; and, like Mulder and Liebig, connect it closely with albumin, but point out that it is somewhat richer in nitrogen. The coagulated form of it however, with a smaller percentage of nitrogen, closely 


\section{I76 O'Brien.-The Proteids of Wheat.}

corresponds to the albumin both of blood-serum and of white of egg. It is in fact suggested that fibrin, existing in the plant in a soluble state, may be the mother-substance which gives rise to albumin as a secondary product. Though glutine and myxon are described as isomeric, yet the former is placed with the vitelline of egg-yolk outside the group of true proteids; whilst myxon is named caseine. So closely however is it also allied to albumin that the question arises, 'Is it indeed true casein, or a modification of albumin which has some of the properties of casein?' There is here an important difference from Liebig, according to whom casein is represented in the vegetable kingdom by legumin, and does not occur in wheat. We may notice that Dumas considers legumin as a mixture of casein and albumin with a third substance richer in nitrogen; whilst Rithausen later classifies legumin as a vegetable casein, with zymom (gluten-casein), and not with any part of the alcohol-soluble proteid of gluten (glian).

Thus more than fifty years ago some of the problems of modern vegetable physiology were at least clearly stated : and though perhaps the outlines of the classification of proteids may be for the present considered settled, yet the position of the characteristic proteids of wheat is no better defined than it was half a century ago, and the questions then raised as to the possible transformation of one form into another are still without satisfactory answer.

No further addition seems to have been made to the knowledge of gluten till about 1860 , when we come to the work of Von Bibra, Günsberg, and Ritthausen. Although in the interval an important step in the investigation of the proteids of the blood had been made by Denis, the advance in animal physiology did not affect the methods of vegetable physiology till nearly i 870 .

Von Bibra ${ }^{18}$, writing in 1860 , seems (as quoted by Ritthausen) to have kept to the subdivisions of Berzelius and Dumas, viz., fibrin [zymom], Pflanzenleim [glutin], casein [myxon].

Günsberg ${ }^{19}$ (I 862) comments severely on the confusion of 
terminology in the subject and goes back to the position in which the matter was left by Taddei, gluten being resolved into zymom and gliadin [glian]. Though he rejects myxon as a distinct body, considering it but a mixture of Pflanzenleim and gluten-particles, yet he does not consider gliadin to be a single substance. Its separation he effects by means of boiling water into: (I) a 'leimartig' substance, soluble in boiling water, and (2) a residue soluble only in alcohol. The former is richer in nitrogen $(\mathrm{I} 7.78 \%$ ) than gliadin $(\mathrm{I} 5.88 \%)$, the residue is poorer $(14 \cdot 10 \%)$. The latter seems very like what I have described as myxon; the former seems to consist of glutine and mucine, for a part of it is soluble even in cold water. The important point seems to me to be this, that by the use of boiling water instead of boiling alcohol the division line between the soluble and insoluble parts of glian (never a hard and fast one) is now drawn at a different place. Unfortunately, in this as in many other cases, no account is given of the proportion in which these different constituents appear in gluten.

Ritthausen ${ }^{22}$ may next be mentioned, for his researches go back beyond I 860 , though his complete results were only published in 1872. He thus classifies the proteids of seeds :

I. Plant-Albumin.

2. Plant-Casein a. Legumin.

b. Gluten-casein [Zymom].

c. Conglutin.

3. Plant-Gelatine (Pflanzenleim) or Gluten-proteids.

a. Gliadin or Pflanzenleim [Glutine].

b. Mucedin [Mucine].

c. Gluten-fibrin [Myxon].

Whence it will be seen that he ignores the work of animal physiologists and hardly attempts to bring vegetable proteids into line with those of the animal kingdom: a position which he defends later $\left(1877^{24}\right)$, insisting on the differences of ultimate chemical composition between the various vegetable proteids as well as between these and animal proteids. 
The proteids he obtains from wheat are as follows :

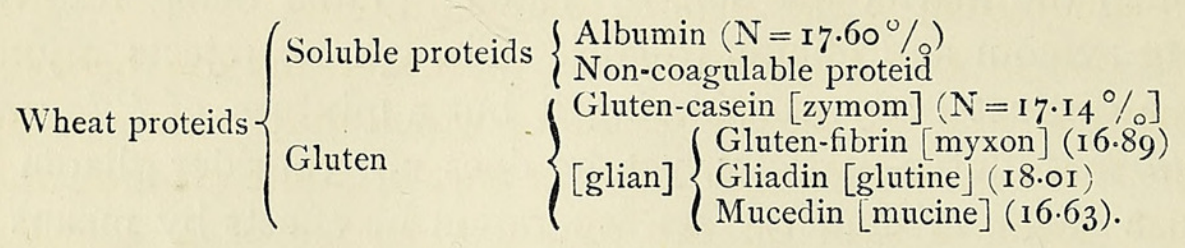

The albumin has a percentage of nitrogen ( 17.60$)$ higher than that obtained by any of the older chemists except Boussingault (18.4). The composition of the albumin is very similar to that of zymom (gluten-casein, $\mathrm{N}=\mathrm{I} 7 \cdot \mathrm{I} 4 \%$ ). Though the amounts of nitrogen differ, a similar relation is seen in the results of Liebig ${ }^{11}$ and Mulder; whilst Dumas and Cahours ${ }^{13}$ make their zymom slightly the richer of the two in nitrogen. In gluten the four constituents already described are recognised; not more than three of them had yet been distinguished by any one writer (except perhaps Günsberg).

Ritthausen's change of name of zymom from fibrin to casein, and the reverse change for myxon, depends rather on the identity of the former with legumin (vegetable casein) than with animal casein. His analyses, however, seem to point to the same conclusion as those of the earlier investigators. Thus he finds zymom richer in nitrogen than myxon (see table); and recent analyses give for fibrin about $17 \%$ of nitrogen (Hammarsten, I6.91), for casein not quite $16 \%$ (Chittenden and Painter, I5.9I; Hammarsten I5.70; Ritthausen I5.46). This is the same relationship as is shown by the results of Dumas: animal fibrin, I6.598, animal casein, I 5.85 ; zymom, I6.4I, myxon, I6.04. The change of name is also based on the results of decomposition with sulphuric acid, and on the greater solubility in dilute acids of the alcohol-soluble proteids. But zymom seems, from Ritthausen's own figures, to be at least as near to the glian-proteids as to the vegetable caseins in the preponderance of glutamic over aspartic acid;

\begin{tabular}{llcccc} 
& \multicolumn{2}{l}{ Veg. Caseins. } & Zymom. & Glian. & Mucedin. \\
Glutamic acid (per cent.) & $\mathrm{I} \cdot 5$ & $4 \cdot 0$ & $5 \cdot 33$ & $8 \cdot 8$ & 25 \\
Aspartic $" \#$ & $3 \cdot 5$ & $2 \cdot 0$ & 0.33 & I. I & $?:$
\end{tabular}


whilst as regards solubility in dilute acids I shall show that this is not great in the alcohol-soluble proteids.

In one or two physical points, moreover, myxon behaves somewhat like the casein of milk; which may more readily than fibrin be made to dissolve in part in dilute alcohol, and which forms a skin on the exposed surface of a solution cooling in the air. So characteristic of Ritthausen's glutenfibrin (myxon) is such skin-formation that it is used to distinguish it from gliadin and mucedin.

A full account is given of the preparation and of the properties of these four substances: I can only point out that they are by no means sharply marked off from each other. Thus myxon is soluble in alcohol $80-90 \%$ in the cold, in alcohol $30-70 \%$ only on heating. Gliadin [glutine] is most soluble in alcohol $70-75 \%$ and is slightly soluble in water; mucedin is somewhat more soluble in water, but is precipitated in the cold by $90-95 \%$ alcohol. In chemical composition zymom is hardly distinguishable from mucedin; as regards solubility they are at the extremes of the series. The proportion in which these bodies occur is said to vary in the gluten of different wheats: and no estimate is given beyond an instance in which zymom formed $28 \%$ of the dry weight of gluten. Gliadin [glutine] is specially variable-on it is said to depend the tenacity and elasticity of gluten.

While these investigators were thus elaborating the knowledge of the constituents of gluten and the composition of particular proteids, others were determining the more general characters of proteid bodies and their relation to each other.

Denis ${ }^{12}$ as early as 1840 had found the value of neutral salts in the separation of proteids. Though his special work was on the blood ${ }^{17}$, yet he described a substance found in peas, beans, almonds and wheat, soluble in dilute solution of sodium chloride, and precipitated from it by excess. This he named 'glutine,' believing that there was one vegetable proteid which appeared under the varying forms of legumin, amandin, gluten, vegetable albumin, casein and fibrin.

Kühne ${ }^{20}$ (1864) investigated the composition of animal 
muscle and isolated its characteristic proteid, which he named myosin.

Hoppe-Seyler systematised the work of these and other observers and introduced a simple classification and nomenclature for proteids. The term 'globulin' introduced by Berzelius ${ }^{10}$ for the coagulable proteid of the red blood-corpuscles had been used by Denis in a wider sense. It did not appear in the classification adopted by Hoppe-Seyler in the second edition of his Handbuch ${ }^{21 a}$ (1865), but in the third ${ }^{21 c}$ (1870) it is used as a generic term for those proteids which are soluble in dilute solutions of neutral salts. Myosin and vitellin are described as subdivisions of it: the former name only dates from I 865 (Kühne), the latter was in use at least as long ago as $1842^{13}$. Like Mulder, Dumas, and Liebig, but on surer grounds than had been before possible, he comes to the conclusion that there is no reason for regarding vegetable proteids as in any essential way different from animal.

Weyl ${ }^{23}$, carrying out the ideas of Hoppe-Seyler as regards vegetable proteids, published in 1877 a paper which called forth vigorous opposition from Ritthausen. In it he claims to have proved the complete identity in chemical behaviour of vegetable and animal proteids. He finds that globulins constantly occur in plants, and suggests that the legumin and casein hitherto described are derivates formed from these by the reagents (alkalies or acids) used in their extraction. His chief generalisations are that (I) the globulins of plants (vitellin and myosin) show the reactions of animal globulins; (2) no albuminates occur in fresh seeds, plant-caseins being secondary products in the seed or artificially produced in manipulation; (3) that by the action of water, acids, and alkalies, all globulins become first albuminates, then coagulated proteids. From seeds formerly described as containing casein, he extracts vitellin (oats, maize, peas, almonds, white mustard, Brazil nuts), or myosin (wheat, peas, oats, white clover, almonds).

To the list of proteids common to plants and animals -globulins, albuminates, and coagulated proteids-Professor 
Vines ${ }^{26},{ }^{31}$ (1 $878-80$ ) added the albumoses, which, as well as globulins, he investigated in the aleuron-grains of many seeds.

The methods and results of Hoppe-Seyler and his school were at first severely criticised by Ritthausen ${ }^{24}$, who noticing only a preliminary account of Weyl's paper, charged him with insufficient observations, and these on a part only of the proteid of the seed. For as the vegetable caseins are insoluble in salt-solution, Weyl must, he contends, have worked only with the substances in the wash-fluids.

The fuller publication of the researches of Weyl left no ground for this argument; and in 1878 Barbieri ${ }^{25}$ made the important announcement that the substances obtained by the methods of Ritthausen and of Weyl are identical in ultimate chemical composition. His work was a careful comparison of different analyses of the proteid of pumpkin seeds, which may be described as casein or vitellin, according to its method of preparation.

This conclusion was accepted by Ritthausen, and both methods were adopted by him in his later investigation ${ }^{27}$ on the proteids of oily seeds. He however rejeeted the idea that there was any need to change his original nomenclature.

The views of Hoppe-Seyler and his principles of classification seem now universally accepted, at least such is the case in England, where they are followed by, among others, Foster, Haliburton, Sheridan Lea, Vines, Green, and Martin. The task of modern botanists is thus simplified; such a scheme of classification being recognised, their work is to bring into line with it all the proteids newly investigated or already described. This is gradually being done for one substance after another; but the attempts to co-ordinate the proteids of gluten with other vegetable proteids hardly seem as yet to have been successful. And if I am unable to assign them to their true position, it may not be quite without use to have indicated that this is still to be done.

An investigation, in 1880 , of the origin of gluten was undertaken by Weyl ${ }^{28}$, in conjunction with Bischoff, which does not seem to have been so successful as his former work. It led 
him to the conclusion that gluten is formed by the action of a ferment on the myosin which he had already described as the chief proteid of wheat. This theory is based on the observations that flour extracted with salt-solution $(\mathrm{NaCl})$ yielded no gluten, and that flour kept for some time at a temperature of $60^{\circ} \mathrm{C}$. likewise lost its gluten-forming power. At the same time the authors admit that no ferment can be isolated, and that the addition of fresh flour to that injured by heating to $60^{\circ} \mathrm{C}$. does not improve the yield of gluten, as should be the case were it dependent only on the presence of a ferment. Moreover they themselves suggest that coagulation of the myosin, not the destruction of a ferment, may be the cause of the non-formation of gluten after the heating of flour.

Johanssen ${ }^{38}$, treating of gluten in 1888 , proposes to himself the following questions: (I) How does gluten form in the washing operation? (2) What tissues of the grain take part? In reply to the former he states that he finds the ferment theory unnecessary, and seems to imply that gluten occurs as such in a finely divided state among the other remains of the inner endospermecells. The answer to the second emphasises what Schenk (III. 6) from another point of view had stated in I 872 , that the so-called 'Kleberzellen' contain only aleurongrains and not the gluten (Kleber) itself. Johanssen finds (I) that a temperature of $60^{\circ} \mathrm{C}$. does not injure the glutenforming power of flour; (2) that an artificial flour formed by mixing powdered gluten and starch behaves in every way like ordinary flour. Hence it is probable that gluten exists as such in flour. The retarding effect of cold and of saltsolutions is ascribed to the less perfect moistening of the gluten-particles, the favourable effect of heat to the greater cohesiveness of the particles, while its inhibitory effect at a high temperature is due to coagulation.

Kjeldahl's ${ }^{37}$ results I can only state as quoted by Johanssen. A minimum and a maximum temperature may be determined, limits beyond which no gluten-formation occurs ; $40^{\circ} \mathrm{C}$. is the optimum. There is a close correspondence between these temperatures and the minimum, optimum and maximum for 
fermentation. Mercuric chloride fixes the proteid of flour and so prevents gluten-formation, whilst it is promoted in poor flour or even in barley-meal by the addition of a small quantity of good flour.

Martin ${ }^{35}$ (I 886) at once supports the ferment-theory, and, following up Weyl's researches, tries to bring the proteids of wheat into line. with the more typical proteids-two propositions which are by no means dependent on each other. Finding in an extract of flour made with water or $10 \%$ salt-solution, (I) an albumose, (2) myosin, he considers these as the precursors respectively of (I) the insoluble phytalbumose (glian) and (2) the fibrin (myxon), which together constitute gluten. The two latter substances differ from the former in their insolubility in cold water and saltsolutions, and the solubility in alcohol acquired by the albumose.

Balland's ${ }^{32}$ long series of observations (1 $883^{-93}$ ) on wheatflour gives results differing from many of those used in support of the ferment-theory. Thus he finds that gluten may be made from flour which has been kept for some time at $80^{\circ}$ or even at $100^{\circ} \mathrm{C}$.; that it may be obtained at $2{ }^{\circ} \mathrm{C}$. from flour previously kept at $-8^{\circ} \mathrm{C}$.; and that its formation is in some cases actually promoted by the use of salt-solutions. He concludes his last paper, written in $1893^{42}$, with the words : Le gluten préexiste dans le blé.

The opinion current among practical bakers may be gathered from the statement of Jago ${ }^{34}$, that gluten exists in flour as a fine powder, swelling up on addition of water into the well-known tenacious mass.

On the one hand, therefore, is the theory of gluten-formation by ferment-action, supported by Weyl and Bischoff, Kjeldahl and Martin : on the other hand, the pre-existence of gluten in flour is maintained, on apparently sufficient grounds, by Johanssen and Balland. The question, then, of the origin and formation of gluten, like that of the nature of its proteids, is one which has not yet received a final answer. 
II.

My own observations on the proteids of flour may be described under the following headings :

$A$. Action of water on flour.

i. Globulins.

ii. Proteose.

iii. Gluten.

Substances derived from gluten : zymom; glian, including myxon, glutine, mucine.

$B$. Action of solutions of salt $(\mathrm{NaCl})$.

C. Action of Alcohol.

Albuminate.

$D$. Relation between gluten and the albuminate.

A. Action of Water on Flour.

The addition to wheat-flour of about half its bulk of water causes, as is well known, the formation of a thick tenacious paste whose characteristic properties are due to gluten, a nitrogenous elastic substance in which the starch, cell-walls, and other parts of the inner endosperm of the wheat-grain are at first embedded. So coherent, however, is the gluten-mass that by prolonged washing in water these other substances may be almost entirely removed, crude gluten remaining behind. Fat and colouring-matter may be removed by ether; but it is impossible to get rid of the last traces of starch.

Gluten, however, does not constitute the whole of the nitrogenous matter of the flour; the washings of gluten also give proteid reactions, and two kinds of proteid may be distinguished. When the slightly acid liquid thus obtained by washing is neutralised, no appreciable precipitate is formed : therefore no acid-albuminate is present. On boiling, however, coagulation occurs, indicating either globulin or albumin; on removal of this by filtering, the solution still gives proteid reactions, so that a proteose or a peptone must also be present. As the whole of the proteid matter originally present in the washings is precipitated by saturation of the solution with magnesium sulphate, the presence of albumin and 
of peptone is precluded: the proteids present must therefore be globulin and proteose respectively.

Thus, as obtained by water, the proteids of wheat are:

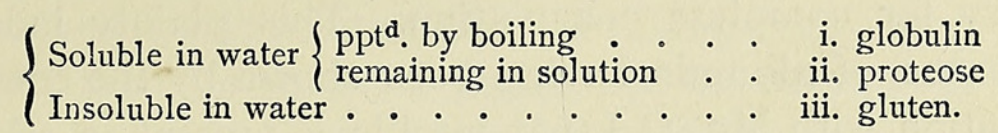

However, these apparently simple facts by no means explain the whole matter, since the amount of gluten obtainable from even the same flour seems to vary with varying conditions. Thus we are told that the yield of gluten is increased by allowing the paste to stand for some time before washing it (Bénard and Girardin ${ }^{29}$, Balland ${ }^{32}$ ); or by the use of 'hard' rather than of pure water (Ritthausen ${ }^{22}$ ): whilst heating of the flour to $60^{\circ} \mathrm{C}$., or extraction of it with salt-solution $(\mathrm{NaCl}$ $15^{\circ} \%$ ) (Weyl and Bischoff ${ }^{28}$ ), or with ether (Peligot ${ }^{15}$ ), are alike said to prevent the subsequent formation of gluten on addition of water.

I. Globulin of Flour. In order to allow the water equal access to every particle of flour, so as to obtain the greatest possible amount of water-soluble proteid, the flour was carefully sifted through muslin into the water. Even with this precaution gluten formed instantaneously, but it could readily be removed from the liquid by filtration after the starch had been allowed to settle to the bottom. Globulin was obtained by coagulation of the filtrate by heat as a flocculent white precipitate, drying to a brownish, brittle, semi-transparent, horny mass; or, if the boiling has been prolonged, to a greyish-white, powdery substance. It swells up on the addition of water or alcohol $(75 \%)$ to a somewhat viscid mass. It is difficult to collect and estimate, but seems to form about $1 \%$ of the weight of the flour: $1 \cdot 10 \%$ was the amount obtained by extraction with water, $1.01 \%$ by extraction with $\mathrm{NaCl}$.

The coagulation by heat is accomplished in two stages: about $55^{\circ} \mathrm{C}$. a milkiness or cloudiness appears, indicating myosin; when this is removed by filtering, the solution may be kept at $60^{\circ} \mathrm{C}$. for some hours without further coagulation 
occurring. On gradually raising the temperature, coagulation is found to begin again at from $75-80^{\circ} \mathrm{C}$, and a dense flocculent coagulum is obtained : heat, however, of nearly of $100^{\circ} \mathrm{C}$. is necessary for complete coagulation. This plainly indicates (the absence of albumin having been shown by the complete precipitation with $\mathrm{MgSO}_{4}$ ) that vitellin is present in addition to myosin. This is further shown by the fact that saturated salt-solution extracts a globulin from flour; and perhaps by the tendency to form crystals (see later). Where an estimate was made, I found myosin $.19 \%$, vitellin $.819 \%$; total globulin $1.009 \%$ (cf. total globulin extracted by salt, $\mathrm{I} \cdot 0 \mathrm{I} \%$ ).

It may be noticed that oats likewise contain both myosin and vitellin (Weyl), as do also mustard-seed and peas (Weyl) and maize (Chittenden and Osborne). In fact the distinction between the two classes of globulins, though a natural one in animal physiology, seems by no means well marked in plants. Thus Martin ${ }^{33}$ describes a myosin of papaw-juice coagulating at $74^{\circ}$; and states that the myosin of wheat may become insoluble even at $35^{\circ}-40^{\circ} \mathrm{C}$. Vines suggests the possibility of one form of globulin passing over into the other, i. e. of plant-vitellin becoming myosin. A third and still more soluble form of globulin is described in maize by Chittenden and Osborne. Vitellin is, in solubility, a connecting link between globulins and albumins; like the former, it is insoluble in pure water; like the latter, it is not precipitated by saturation with $\mathrm{NaCl}$, but it is precipitated by $\mathrm{MgSO}_{4}$, while they are not. These typical degrees of solubility are shown by the globulins of wheat (cf. following table, to which albumin is added for the sake of comparison):

\begin{tabular}{|c|c|c|}
\hline $\mathrm{NaCl}$ (dilute) & $\begin{array}{l}\text { Albumin. } \\
\text { soluble }\end{array}$ & $\begin{array}{l}\text { Vitellin. } \\
\text { soluble }\end{array}$ \\
\hline $\left.\begin{array}{l}\mathrm{NaCl} \text { (saturated) } \\
\mathrm{NaCl} \text { (dil., at } 60^{\circ} \mathrm{C} \text {.) }\end{array}\right\}$ & soluble & soluble \\
\hline $\begin{array}{l}\mathrm{MgSO}_{4} \text { (saturated) } \\
\left(\mathrm{NH}_{4}\right)_{2} \mathrm{SO}_{4}\end{array}$ & $\begin{array}{l}\text { soluble } \\
\text { insol. }\end{array}$ & $\begin{array}{l}\text { insol. } \\
\text { insol. }\end{array}$ \\
\hline
\end{tabular}

The globulin of wheat is obtainable also in a crystalline 
form, but as yet I have only been able to prepare it on a very small scale. The globulin is precipitated from its salt-solution by alcohol, filtered, washed with dilute alcohol, and re-dissolved in salt-solution $(\mathrm{NaCl})$. The process of crystallisation can then be watched under the microscope in a drop of this solution. As the water evaporates, the proteid is first deposited on the surface of the slide in hexagonal plates. Usually three of the angles are formed, and then two parallel sides are continued for some time; many of these forms occur side by side, springing from an irregular mass of proteid-a perfectly regular hexagonal plate is rare. Occasionally a large, well-defined, double hexagonal pyramid is seen, or what appears to be a dodecahedron with triangular faces. As evaporation proceeds, the salt is also deposited, either independently in large crystals or else in tiny cubic crystals covering the hexagonal areas laid down, and rendering their outline less distinct. Addition of water of course causes the proteid crystals to dissolve in the re-formed salt-solution; but it is, with care, possible to fix them and so show their proteid nature. Fixing with alcohol was not successfulprobably it was not allowed to act for a sufficient time. But if the slide with proteid and salt-crystals is placed in a concentrated solution of tannic acid, the salt dissolves whilst the proteid is fixed. After careful washing the hexagonal proteid plates remain on the slide, and the pyramidal crystals retain their outline though with a slightly contracted and collapsed appearance. With a saturated solution of picric acid similar results may be obtained, though with greater difficulty, as much care is required in washing away the excess of picric acid. Similar proteid crystals were incidentally observed on a slide on which a section of barley had been left in saltsolution.

The tendency to crystallisation seems strong. Precipitated by alcohol, globulin separates in minute, irregular, flake-like forms, from which, by treatment with $\mathrm{NaCl}$ on a slide or in a watch-glass, crystalline forms may be obtained. Coagulated by boiling, globulin settles out in spheres embedded in a more 
or less homogenous net-like matrix; in addition to the spheres there are many rhombohedra, and apparently transitional forms between these and the spheres, the six faces becoming less distinct and the angles disappearing. These octahedral forms and spheroids seem similar to the crystallised proteids described by Osborne: octahedra occurring in the proteids of Brazil-nut, hemp-seed and oat-kernel, associated with the rhomboid form, with spheroids, and occasionally with hexagonal plates-a form to be expected in association with the others.

ii. Proteose of Flour.-In the watery extract of flour, as well as in an extract made with $\mathrm{NaCl}$ solution, a proteid remains in the filtrate after removal of the globulins by boiling. It is not precipitated by saturation with $\mathrm{NaCl}$, but is precipitated by $\mathrm{MgSO}_{4}$ and also by $\mathrm{HNO}_{3}$ in the cold ; the latter precipitate disappears on heating to reappear on cooling. This indicates a proteose; but the biuret reaction was not satisfactory. A drop of dilute solution of $\mathrm{CuSO}_{4}$ caused a precipitate in the proteose solution, but this did not dissolve in $\mathrm{KOH}$ to the typical red solution; instead, a turbid yellow liquid results, from which a yellowish orange precipitate settles out, perhaps due to reduction by the sugar sometimes present in flour. The proteose was not further isolated; it appears to be present only in small quantities. As it readily gives the characteristic reaction with nitric acid, and is precipitated by copper sulphate, it is probably one of the primary albumoses (proto- or hetero- of Kühne and Chittenden).

Ritthausen and earlier writers had mentioned a noncoagulable proteid obtained in the washings of gluten; it was first described by Martin ${ }^{35}$, who considers it the precursor of the insoluble phytalbumose (? glian) of gluten. Such a transformation seems hardly probable; for the proteoses are themselves probably hydrolysed products of the albumins and globulins, with a smaller molecule; one would expect that further hydrolysis would continue the process towards greater solubility. The corresponding small amount discovered by Osborne in the oat and in the maize-kernel he 
considers secondary, and this may well be the case here likewise.

iii. Gluten.-This may be formed in fine strands on a slide under the microscope by adding a drop of water to a few grains of flour and moving the cover-glass over it. These strands give the usual proteid reactions and stain sharply with various aniline-dyes, e.g. methyl-violet and saffranin. The only at all characteristic stain that I can find is aniline-blue (Wasserblau) or Hoffmann's blue. On addition of either of these, freshly dissolved in water, the gluten-strand gradually colours and swells up, losing its sharp contour-probably owing to the acid nature of the reagent. These strands are otherwise singularly stable, being apparently unaffected by irrigation with solutions of sodium chloride, sodium phosphate, sodium carbonate, and even for some time with dilute potash. In acetic acid they swell up, but on washing or neutralisation appear as fine and complete as before: this is likewise the case with hydrochloric acid ; sulphuric acid acts more strongly, the gluten at first appearing fixed but soon dissolving, in the dilute acid or in concentrated.

In obtaining gluten for quantitative estimation, my method was to add water at $30^{\circ} \mathrm{C}$. to IO-I 5 grams of flour, till a stiff paste was formed. This was left to stand for an hour, and was then washed by moving it gently with a glass rod on a piece of muslin loosely stretched and dipping into a beaker of water at $30^{\circ} \mathrm{C}$.; there is thus no need to allow any particles of gluten to become isolated from the mass. The chief danger of loss is in the particles of gluten which necessarily adhere to the dish in which the paste is formed: they are best collected and washed, at first, independently of the rest. As the starch is removed, the gluten becomes sufficiently coherent to be held in the fingers, and may at this stage be washed under the tap. In a short time the gluten contracts to a tough mass ; in fact throughout the process it is becoming less viscid and elastic. Washing should be continued till the mass of damp gluten pressed on a slide leaves no starchgrains in a drop of water. The prepared Hungarian flour 
which I used yielded about $10 \%$ of crude gluten as dried in bulk at $100^{\circ} \mathrm{C}$., when treated according to the above method of washing. I found however that with a little care, even under what are usually described as unfavourable circumstances, I could obtain the same amount from it, as the following experiments indicate.

(I) Flour was sifted carefully through muslin into a beaker of water; the intention being to dissolve as much as possible of whatever proteid in it was soluble in water. Gluten, however, seemed to form instantaneously; as when the starch had sunk to the bottom, a drop of the supernatant fluid showed strands of gluten under the microscope. This could be collected by filtering: and the whole mass, having been left on the filter during the night, yielded, on washing out the starch in the usual way, 516 gram gluten from 5 grams flour $(10.32 \%)$. Hence it follows that $(a)$ water removes nothing essential to the formation of gluten; and $(b)$ if a ferment is present it must be ubiquitous.

(2) Similarly, to Io grams of flour saturated salt-solution $(\mathrm{NaCl})$ was added; a stiff non-tenacious paste was the result, indicating that gluten had not been formed. On further addition of salt-solution some proteid was extracted (Vitellin, .08 I 9 gram $=.819 \%$. Water was then added so as to produce a dilute salt-solution (about $10 \% \mathrm{NaCl}$ ), and now gluten was recognisable in the liquid; this was collected as before, and a total of I.II 3 grs. was ultimately obtained (Gluten $=\mathrm{II} \cdot \mathrm{I} 3 \%$ ). Myosin $(.019 \mathrm{gr} .,=\cdot 19 \%$ ) was obtained from the dilute salt-extract, by coagulation. Hence the formation of gluten from a globulin in the flour is precluded; for, under these circumstances specially favourable to its collection, only the normal amount $(1.009 \%)$ was obtained.

(3) The fact that gluten was obtained in the usual quantity by forming the paste and conducting the earlier stages of washing entirely with a $10 \%$ salt-solution, further proves its independence of globulin :- IO grams flour yielded $\mathrm{I} \cdot 075 \mathrm{gram}$ gluten, i. e. $10.75 \%$.

(4) Whilst Weyl and Bischoff ${ }^{28}$ found that heating flour at 
$60^{\circ} \mathrm{C}$. destroyed its gluten-forming power, Johanssen ${ }^{38}$ and Balland ${ }^{32}$ consider it unaffected. I found that flour, kept at $100^{\circ} \mathrm{C}$. for thirteen hours in all on two successive days, yielded gluten in the slightly diminished quantity of $9.91 \%$; another result with flour kept at $100^{\circ} \mathrm{C}$. for two hours, on two successive days, was $1 \mathrm{I} .53 \%$; whilst a third result after three hours was the normal amount of $10.625 \%$.

(5) I found that even when boiling water was added to flour at $100^{\circ} \mathrm{C}$. gluten formed apparently to the usual extent ; but owing to the impossibility of readily separating it from the starch-paste simultaneously formed, the weight was not determined. This surely precludes the possibility either of the origin of gluten from globulin; or of ferment-action.

(6) Nor do extremely low temperatures seem to much affect the formation of gluten. Flour was extracted with a mixture of salt and snow, which removed globulin as at ordinary temperatures. On placing the residue on a filter and adding water to remove the excess of salt, a coherent paste formed showing the presence of gluten, and this at a temperature only just above $\circ^{\circ} \mathrm{C}$. The paste was, it is true, less tenacious than gluten at ordinary temperatures; but this in turn is less elastic than gluten at $30^{\circ} \mathrm{C}$.

(7) Gluten was obtained from flour which had been about twenty-four hours in absolute alcohol, as well as from flour which had been moistened with ether or with $75 \%$ alcohol, when these had evaporated. It is to be noticed however that it could not be obtained when the part of the flour which is soluble in $75 \%$ alcohol was extracted; though, as has been already mentioned, it could be readily obtained when the constituents soluble in salt-solution were removed.

When dried, gluten is semi-transparent, yellowish-brown, and glue-like in appearance; of an opaque whitish-yellow when moist. When dried in a mass of about I gram at $100^{\circ} \mathrm{C}$., it loses above $50 \%$ of its weight: so that where it has been necessary to calculate I have used $44 \%$ as the amount of dry gluten in the crude moist mass (unless the percentage had been separately determined for the gluten in question). The 
relative accuracy of this is confirmed by adding the amount of zymom (28.3) and glian (1.5.32) obtained from moist gluten : they give $43.6 \%$ for the dry weight. Probably not more than $40 \%$ is pure gluten, for further loss of water may be effected by drying in a finely powdered state; and starch and other impurities are present. It may be dried at $100^{\circ} \mathrm{C}$., and be kept for months without losing its power of becoming tough and elastic with water-as I found contrary to what is frequently stated. On dehydration with absolute alcohol it becomes a white powdery mass, which resumes the typical characteristics of gluten on being moistened.

The solubility of gluten has been fully described by Ritthausen. It is soluble in dilute acids and alkalies-but for complete solution especially in acids I found that considerable time was needed even at ordinary temperatures: at the low temperatures employed by Ritthausen it seems to have taken place fairly readily. I found that gluten, though less readily soluble in sulphuric than in other acids, was ultimately attacked by it. A $5 \%$ solution of sodium carbonate acts so slowly that one can use it for making the paste and also for washing for some time before the gluten is attacked.

In water, gluten is insoluble-as one would expect from its mode of preparation : all the proteid soluble at ordinary temperatures being removed by the water used in washing. The same is true for a solution of sodium chloride. The fact that water in which gluten has stood for three or four days gives an albumose reaction simply indicates the gradual formation of this from gluten.

In boiling water, however, gluten is to some extent soluble; as pointed out by Guinsberg ${ }^{19}$ and by Martin ${ }^{35}$. The latter describes the part soluble in boiling water as 'insoluble phytalbumose,' and makes it coincide with the part of gluten soluble in alcohol [glian]. According to Günsberg, however, although the part soluble in water is completely soluble in alcohol, the converse is not true. This I likewise find to be the case : and it may be proved in the three following ways. (I) If the clear alcohol-extract of gluten [glian] be poured 
boiling into even a large quantity of boiling water some of it is at once precipitated: nor can it in any way be made to dissolve. (2) If an extract of gluten is made with boiling water and cooled, the 'insoluble phytalbumose' appears as a cloudy precipitate: this may be readily dissolved in the cold by the gradual addition of alcohol to form a dilute alcoholic solution. Thus whilst the 'phytalbumose' is entirely soluble in dilute alcohol, glian is only partially soluble in boiling water. (3) The following method was employed to determine the actual amount of gluten soluble in boiling water and in alcohol respectively, i.e. the quantities of 'phytalbumose' and of glian to be obtained. A piece of freshly prepared gluten was divided into three parts, each consisting of about 2 grams. One part was dried, in order to show the proportion of gluten in the moist mass. Another part was cut into small pieces, exhausted with alcohol, and the residue dried and weighed. The third part was likewise cut into small pieces; these were dropped into a large amount of water (about I litre) at $100^{\circ} \mathrm{C}$., and were almost immediately collected on a filter and washed with boiling water till no more proteid was extracted. The residue obtained in this way could not consist of any part once dissolved and then coagulated. The difference between the residue and the dry weight of the gluten employed in each case was calculated : it represents the amount which had passed into solution as glian and phytalbumose respectively.

$$
\begin{array}{cccc}
\text { Phytalbumose } & 6.2 \% & \text { Glian } & 26.6 \% \\
\text {, } & 7.84 \% & \# & 35.06 \%
\end{array}
$$

The phytalbumose-solution gives the general proteid reactions, and, as Martin has described, those characteristic of an albumose. A part of it [mucin] remains in solution even in the cold, and is described, under the name of mucedin, by Ritthausen, as one of the essential constituents of gluten. But as it cannot be extracted from gluten in the first place by water at ordinary temperatures it is probably a secondary product resulting from the action of boiling water. Water 
at ordinary temperature may be made to produce a similar albumose from gluten, but only by prolonged contact, i.e. more than three or four days. The insoluble albumose of gluten has been regarded as an insoluble derivate of the soluble albumose of flour (as extracted by water in the washings of gluten). The behaviour of gluten, once prepared, towards water on standing and towards boiling water, indicates rather a derivation of a soluble albumose from a less soluble form of proteid; and perhaps the proteose of the washings of gluten is similarly derived from gluten in its earliest and (as will be shown later) its most soluble stage. In this case, the connexion between the albumoses would be as follows: as much as can be at once formed by cold water is removed in the washing, but more is subsequently formed by boiling water and removed as mucin, together with the intermediate insoluble phytalbumose.

The solubility of gluten in alcohol leads directly to the question of the constitution of gluten; for, as has been already shown, alcohol has been chiefly used in its analysis. The products thus obtained have been mentioned in the historical sketch, and may here be tabulated :

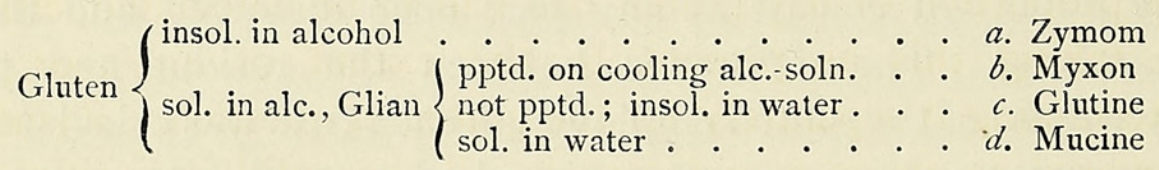

This is by no means to be taken as a statement that gluten consists of four different constituents, which may be separated in the way indicated by their solubilities. It is simply an acknowledgement of the fact that by treating gluten in certain ways certain corresponding products may be obtained, for each of which it is convenient to have a name. They have frequently been considered as distinct substances which exist independently in gluten; but it seems to me that we might with equal justice consider cane-sugar to be merely a mixture of dextrose and laevulose, because on hydrolysis it yields these two bodies. There is, moreover, direct evidence against their existence as independent constituents of gluten; this 
is afforded by the fact that the amount obtainable of any one of them may be made to vary by varying treatment of the gluten.

a. Zymom.-Zymom is most simply prepared by boiling gluten in alcohol; but thus obtained it may have passed into the coagulated state, and may moreover contain some of the glian which has become coagulated. To avoid this it may be prepared by carefully washing gluten at ordinary temperatures with alcohol: at first of about $60 \%$, then of $65 \%$, and so on up to $90 \%$ (Ritthausen). Even as thus obtained, its solubility is less than that of gluten as a whole; especially is it less soluble in acids, which points to its having undergone some change in the process of separation. The estimates given of its amount differ: Ritthausen states it as $28.3 \%$ of pure, dry gluten; Von Bibra as $70 \%$ of crude gluten, probably corresponding to about $62 \%$ of pure, dry gluten; Taddei's zymom represents one-third of the volume of moist gluten. The following estimates agree on the whole with those of Von Bibra. The process of exhaustion with alcohol was effected by means of the condensing apparatus to be described later, the gluten being cut into small pieces. Moist gluten was used, so that the proportion of dry gluten has had to be calculated, either by taking this as present to the extent of $44 \%$, or by determining it separately for the gluten in question. Zymom prepared as above would contain all the solid impurities of crude gluten, so that about $20 \%$ has been allowed for this to give the results of the third column-the calculated proportion of zymom in pure dry gluten.

Percentage of Zymom in Gluten.

$\begin{array}{lcc}\text { I. Moist. } & \text { 2. Crude dry. } & \text { 3. Pure dry. } \\ 28 \cdot 9 & 64 \cdot 89 & 56 \\ 32 \cdot 14 & 70 \cdot 3 \mathrm{I} & 64 \\ 35 \cdot 26 & 78 \cdot 35 & 74 \\ 27 \cdot 5 & 64 \cdot 94 & 56\end{array}$

The results vary considerably; roughly speaking, about $70 \%$ of crude, $50-60 \%$ of pure dry gluten, is insoluble in alcohol, i. e. consists of zymom. Differences to the above extent might have been expected, because of the difficulty of weighing 
moist gluten in the same state in each case; also because different specimens of gluten must contain different proportions of impurity, and a different degree of hydration may have been attained in the washing of each.

More important, however, than the actual amount of zymom present, is the fact that the amount may be made to increase by placing gluten in circumstances favourable for hydration: as in water or dilute sulphuric acid. Absolute alcohol is practically without effect ; prolonged action of dilute sulphuric finally causes a dissolution of the zymom already formed. The results are shown in the following table, the columns indicating, as above, the percentage of zymom in (I) moist, (2) dry, crude, (3) pure, dry gluten. The results, $A$, were obtained from equal weights (about 2 grams) of the same gluten; $B$, similarly, from gluten prepared at another time.

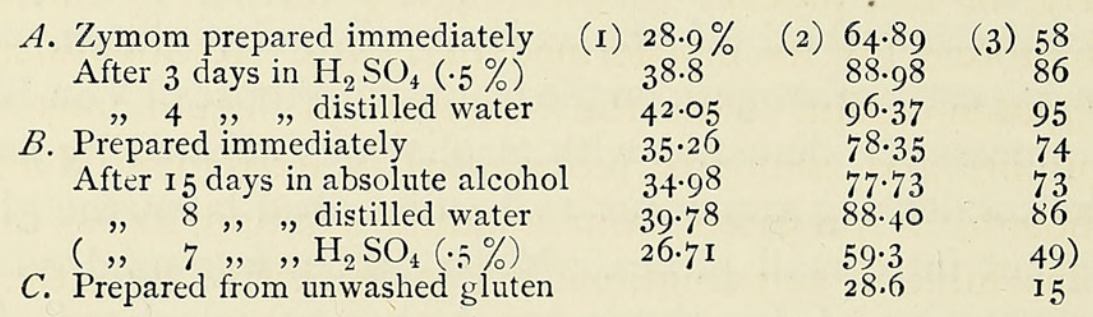

That the $70 \%$ of zymom found in crude gluten which has been washed for some hours in the usual way, is in excess of that originally present, is shown in the result $C$; the amount of zymom present in just-formed gluten being estimated as follows. Five grams of flour were made into a paste in the usual way for gluten-formation; but the paste, instead of being washed with water to remove starch, was extracted with alcohol, and the glian was collected, dried, and weighed. From the flour employed, $10.5 \%$ of crude gluten was obtainable, of which about $70 \%$ consists of zymom. From the .5 gram of gluten thus present in the 5 grams of flour employed, $\cdot 357$ gram glian was extracted, leaving $\cdot$ I 43 gram zymom, or $28.6 \%$, corresponding to $15 \%$ of the pure gluten present.

Hence, during the process of washing, the amount of zymom 


\section{O'Brien.-The Proteids of Wheat.}

increases from $15 \%$ to $70 \%$, and by continuing the process further the amount may be increased to as much as $95 \%$. There is thus no hard and fast line between zymom and the alcohol-soluble constituents of gluten. In this connexion we may consider the fact mentioned by many writers on gluten ${ }^{29},{ }^{32}$, that by allowing the paste to stand for some time before washing; considerably more gluten may be obtained than by at once proceeding to wash it; this may be due to the process of hydration having meanwhile gone on and diminished the danger of loss in washing.

Thus the identification of the more insoluble part of gluten (zymom) with any simple proteid seems impossible; it being, as is obvious from the above results, a secondary product. In the first place it is derived from the mother-proteid as it occurs in flour by the addition of water; later, and more slowly, in the process of washing, by further hydration of this proteid (or its first-formed derivate). Its identification, as 'gluten-casein,' with the 'caseins' of leguminous seeds (legumin) and almonds (conglutin) is extremely doubtful. Although, as prepared from alkaline solution, these caseins are insoluble in salt-solutions, yet in the native state they are extremely soluble, conglutin dissolving readily even in water: admittedly, however, zymom is the most insoluble part of gluten, itself a rather insoluble form of proteid!

b. Myxon is described by Ritthausen as hard to estimate: he finds $2-3 \%$, but suggests that the amount is probably larger; von Bibra finds $8.8 \%$. As the amount present seemed to me to vary with every change in temperature, and in the strength of the alcohol, I have not tried to estimate it. It is described by Ritthausen, under the name of 'glutenfibrin,' as hard, brittle, and transparent, as soluble in $90 \%$ alcohol in the cold, and as losing part of this solubility on drying in the air at ordinary temperatures (a change which might equally well be described as a partial transformation into zymom). It is characterised as being the only constituent of glian which forms a skin on the surface on the cooling of an alcoholic solution, and is said to diminish the softness and 
tenacity of gluten; but after being washed, and dried even at $100^{\circ} \mathrm{C}$., it seems to me to possess a considerable amount of elasticity, and though as precipitated from a solution which has boiled for some time it is less sticky, yet it still coheres on drying.

An alcoholic extract of gluten (i. e. a solution of glian), even when perfectly clear, may become cloudy on standing in the cold; on heating, the precipitate thus formed disappears, to reappear on cooling: hence myxon, not originally present, has formed on standing. This process may be repeated several times, the myxon precipitated each time on cooling being filtered off, more is formed on standing. It seems impossible, even by cooling to $\circ^{\circ} \mathrm{C}$., to separate between the part which is soluble in the cold in alcohol and that which is not, viz. myxon. Prolonged boiling, too, even when the solution is kept at the strength of about $80 \%$ alcohol, converts more and more of the glian into myxon: this is not a case of ordinary coagulation, which takes place most readily when there is a large excess of water. All this surely points, not to the definite presence of myxon as a constituent of gluten, but to a gradual change in the solubility of the proteid (glian) at first soluble in alcohol: for if the precipitate first described were merely due to loss of alcohol by evaporation, it should disappear on replacing the loss by addition of alcohol, but this is not the case; again, if the precipitate on cooling is simply due to change of temperature it should disappear on warming, but this is only partially the case. More and more glian is converted into myxon, and the myxon finally becomes coagulated, and no longer capable of dissolving even by means of heat. The first part of the change, however, i.e. into myxon, is not coagulation, for myxon is still soluble in dilute potash $(.5 \%)$, although with its loss of solubility in alcohol in the cold it has lost likewise its solubility in acetic acid.

I must, however, admit that I did not succeed in making all the glian pass over into the myxon form, even by keeping it boiling for some hours each day for more than a week. 
c. Glutine.-This originally constitutes the greater part, if not the whole, of glian; and, as shown under zymom, glian constitutes in the first place about $85 \%$ of gluten. In gluten prepared in the usual way, however, only $30 \%$ of glian is present; and of further hydrated gluten only $5 \%$ is soluble in alcohol. Glutine is the most important constituent of gluten, and on the proportion in which it is present depends the tenacity and elasticity of gluten-in fact, its value from a commercial point of view. It is, too, the constituent richest in nitrogen (Ritthausen, $\mathrm{N}=18.01 \%$ ) approaching in this the conglutin (casein) of almonds, as indicated by Ritthausen in the name of the latter, although, as we have seen, it was the part of gluten insoluble in alcohol (zymom) which he called gluten-casein. This richness in nitrogen is not so evident in the ressults of other analysts; and the smaller percentage in the other derivates of gluten may be due rather to their having taken up a small amount of water than to an originally different composition.

It is soluble in alcohol of about $75 \%$ strength, and is not completely soluble in water. Ritthausen found that the part soluble in water contained $17.7 \%$ nitrogen, the insoluble part $16.6 \%$ (These results being obtained from glutine with $18.13 \% \mathrm{~N}$, may support the remarks just made as to the diminution in the percentage of nitrogen; whilst that the soluble part had on drying lost its solubility in alcohol and in acetic acid may also be noted.) I find, however, that a solution from which as much myxon as possible has been separated, gives but a slight precipitate on adding to a large quantity of boiling water; that is, that all the glian has passed over either into the myxon form or has become of an albumose nature. Glutine is not easily coagulated; but if a freshly prepared solution be poured into a large quantity of boiling water large clots may form on boiling. From a solution of glutine, therefore, we may obtain (I) a less soluble form of proteid, myxon, by boiling with alcohol; or, (2) a completely coagulated form by boiling with a large quantity of water.

The term glutine comes in this way to include a good deal 
of what I have for the sake of convenience called myxon, what Ritthausen distinguished as gluten-fibrin and earlier writers as gluten-casein, which is ultimately insoluble, but which at first, as I have shown, possesses the solubility in alcohol in the cold which is typical of glutine. And it must be remembered that even the first precipitated part of myxon, not less than glutine, is soluble in cold alcohol, if of the right strength, i.e. $90 \%$, though in alcohol of $60-70 \%$ heat is necessary for its solution-so that between it and the myxon later produced by standing or heating, the difference is only one of degree. Hence the term glutine comes ultimately to include all of myxon, and is really co-extensive with 'glian' in signification.

The chemical properties of glutine, or of a freshly-prepared glian-solution, are those of a proteid. With Millon's reagent, however, the precipitate or coagulum never becomes deep red, remaining somewhat salmon-coloured. The tint of the potash solution of the copper sulphate precipitate, being reddish rather than violet, indicates something of an albumose nature, as does also the greater solubility in hot than in cold alcohol. The solution also gives the reactions described by Osborne ${ }^{41}$, as characteristic of 'Zein' (see p. 203).

d. Mucin has already been partly considered in treating of the solubility of gluten in water; and the impossibility of its existing as such in gluten was inferred from its non-extractability by cold water. In composition it approaches myxon (Ritt.), and has in fact the typical average composition of pure gluten. Its solution gives the characteristic reactions of a primary albumose, and it resembles glutine except in its non-coagulability.

These are the chief facts gathered from the study of gluten. Collected they seem to indicate :-

(I) That the differently described alcohol-soluble derivates of gluten merge into one another;

(2) That the alcohol-soluble portion may be made to pass over into the insoluble stage;

(3) That a proteose is readily formed as a secondary product from gluten. 
It is next to be considered whether the treatment of flour with other reagents than water throws light on the composition of gluten. Dilute potash hardly seemed likely to do so: for it would have no discriminating power between gluten and the globulin and proteose of flour; all of which it would dissolve as well as such other parts of the cell-protoplasm as might still persist. Salt-solution $(\mathrm{NaCl})$ and dilute alcohol seemed more likely, and were therefore used, with the following results.

\section{B. Action of Salt-Solutions.}

Weyl ${ }^{23}$ had found in 1877 that by solution of salt $(\mathrm{NaCl}, 10-15 \%)$ a globulin (myosin) is extracted from flour. In $1880^{28}$ he tried to trace the connexion of this with gluten, and, failing to obtain gluten from flour after extraction with salt-solution, he concluded that myosin is the mothersubstance of gluten.

I found, however, that salt-solution extracted exactly the same proteids as water, and these in exactly the same amount, about $1 \%$-an amount quite out of proportion to the amount of gluten. As mentioned (page 190) in describing the formation of gluten (2), the salt-solution was added in the way considered most likely to prevent gluten-formation.

I. Flour treated with a $10 \%$ salt-solution behaves in the same way as when treated with water. That is, gluten is formed in about the same quantity, and a globulin and a proteose occur in the washings.

2. If a concentrated salt-solution be added to flour, no gluten at first forms, and a small amount of globulin (vitellin) may be extracted. On dilution of such a mixture, or on addition of water to the residue after the salt-solution is poured off, gluten forms in the usual quantity and more globulin (myosin) passes into solution.

The proteids extracted by salt are the same in nature and amount as those extracted by means of water; and after exhaustion of flour by water, salt-solution extracted nothing further. In both cases, however, alcohol $75 \%$ subsequently 
extracted the proteid to be described later as the albuminate; or more properly, it extracted glian from the gluten which must in each case have formed.

No information is thus directly added as to the nature of gluten, but some facts about its origin are made clear, which will be considered later.

\section{Action of Alcohol.}

If gluten existed as such in flour, we should expect it to yield its glian-elements to alcohol; finding that alcohol $(76-80 \%)$ yielded only fat, Martin ${ }^{35}$ concluded that not gluten, but some precursor of it, exists in flour. Ritthausen, however, found that with alcohol he could extract proteids of his third class (gluten-proteids) from flour. The amount extracted was from 4.3 to $5.5 \%$ of the dry weight of flour. My results were somewhat higher.

Alcohol $(75 \%)$ forms with flour a smooth paste whose want of elasticity indicates the non-formation of gluten. A larger quantity of alcohol extracts a proteid and leaves a residue which gives no gluten and no globulin. The absence of gluten in the residue is the result of the removal of the proteid, not of any inhibitive action of alcohol; for flour moistened with $75 \%$ alcohol, which was allowed to slowly evaporate, ultimately yielded the normal amount of gluten. The want of globulin is probably due to the coagulating effect of the alcohol, for the process of extraction is always a lengthy one. That the globulin is not extracted as such in the alcoholic solution is seen in the absence of any coagulum on heating. Salt-solution subsequently extracts a small amount of proteid; it is precipitated by ammonium sulphate, but not by saturation with salt $(\mathrm{NaCl})$ or by heat-agreeing with the proteose originally extracted by salt-solution or by water.

The alcohol-extract contains a proteid, giving the xanthoproteic and Piotrowski's reactions, and with Millon's reagent a strongly coagulated precipitate which, like that in glian, does not colour deeply on heating. The proteid is not coagulated by heat; it is precipitated by alcohol or water, but passes 


\section{O'Brien.-The Proteids of Wheat.}

again into solution when water or alcohol is added till the previous proportion is approximately restored. Towards dilute salt-solution it behaves as towards water, a precipitate being formed which disappears on slight addition of alcohol. It is precipitated by ether, but the precipitate disappears on dilution with water or on evaporation of the ether. These are all obviously phenomena due to successive hydration and dehydration.

The solution is slightly acid, and on neutralisation with potash a precipitate is formed. This is of a different character from the hydration precipitates already mentioned, for it redissolves, not on addition of alcohol to the original strength, but on further addition of potash. This solution may be precipitated by dilute acid: the precipitate thus formed is, however, not soluble in dilute acid, but redissolves in $75 \%$ alcohol. That is, dilute alkali $(\mathrm{KOH}, \cdot 5 \%)$ can convert the proteid into an alkali-albuminate, whilst dilute acid $(\mathrm{HCl}$, $.5 \%$ ) cannot transform it to an acid-albumin. May this be taken to indicate that it is of itself acid in character, and thus incapable of playing the part of a base to other acids? The explanation offered by Chittenden and Osborne ${ }^{41}$ of the somewhat similar behaviour of zein (from maize) is that a true albuminate is not formed; the proof being in the insolubility of the precipitate in excess of acid, whilst it is soluble in $75 \%$ alcohol. The characteristic tests for zein were applied to the alcohol-soluble proteid with the result that exact agreement of behaviour was shown. It was examined (I) as precipitated by ether, (2) by absolute alcohol, (3) after evaporation to dryness, with the same results. $\mathrm{HCl}\left(\mathrm{I}_{\%} \%, \mathrm{HNO}_{3}\right.$ (dilute), do not dissolve it; $\mathrm{KOH}(1 \%)$ and $\mathrm{Na}_{2} \mathrm{CO}_{3}(5 \%)$ dissolve it, and it is precipitated unchanged from the alkaline solution by acetic or hydrochloric acid, i.e. the precipitate is soluble as before in $75 \%$ alcohol, in dilute alkalis, but not in dilute acids. The process may be several times repeated. Strong alkali, or prolonged heating with dilute, destroys the solubility in alcohol, and renders solution in acids possible.

This proteid resembles the proteoses in many points. It 
is more soluble in hot water than in cold; if precipitated by standing from its alcoholic solution, it, at first, disappears on heating. It gives the proteose reaction with nitric acid; but the biuret reaction is doubtful, a violet tinge being always present. As it exists in the alcoholic solution, it is, however, obviously a hydrated proteid, which may be readily dehydrated by addition of alcohol or ether; it cannot, therefore, have reached the proteose stage. It corresponds rather to an albuminate, using the word in the sense suggested by Weyl ${ }^{23}$ and adopted by Osborne ${ }^{33 a}$, i.e. to a primary proteid hydrated by means either of water, acid, or alkali. Here the hydration is by means of the water in the dilute alcohol; for if the acid present were sufficient to form an acid-albumin, this would be extracted from flour by water, which is not the case. A further degree of hydration is reached if the albuminate is allowed to stand with a large amount of water; a degree of hydration which seems to correspond to that of gluten, as will be further discussed later. Finally, by boiling, the stage of coagulation is reached, and all but an inappreciable part may be made to coagulate (as is likewise the case with the ultimate constituents of gluten). Or the insoluble stage may be reached by evaporation in the cold and re-solution in dilute alcohol of as much of the proteid as will dissolve-a constantly diminishing quantity. In this, as in chemical behaviour, it resembles zein, which can be similarly made to pass into an insoluble form, in which it is unchanged in ultimate chemical composition (Chittenden and Osborne ${ }^{41}$ ).

The proteid extracted by $75 \%$ alcohol, when dried at ordinary temperatures, forms a clear brittle glue-like mass. This is sometimes the case on drying at $100^{\circ} \mathrm{C}$., but if a large amount of liquid has been used, the process is long enough for coagulation to occur in the watery solution towards the end of evaporation. During evaporation a sticky layer is deposited on the sides and bottom of the dish, and a pellicle forms on the surface (indicating the presence of myxon). The dried substance takes up water readily, forming a transparent, viscid mass somewhat resembling gluten : it is, however, more sticky, 


\section{O'Brien.-The Proteids of Wheat.}

and may be drawn out into elastic strands giving under the microscope the aniline-blue reaction mentioned under gluten.

When the alcoholic solution is precipitated with water before evaporation and water added during the process, the physical properties of the albuminate obtained are considerably changed. It forms a tough opaque, rather than a clear viscid mass ; in fact, it is now almost indistinguishable from gluten prepared in the usual way. This form likewise exactly resembles gluten in its behaviour to alcohol.

$50 \%$ alcohol extracts a similar albuminate, but not so completely, since gluten-strands form in the residue. Also, though globulin cannot be dissolved out from the residue, it may be found as minute spherical particles in suspension on addition of water. Besides this globulin, only a trace of proteid is obtained by subsequent addition of water ; magnesium sulphate giving only a slight precipitate, and heat causing only the faintest milkiness.

$80 \%$ alcohol extracts an albuminate of exactly the same nature as that extracted by alcohol $75 \%$.

$90 \%$ alcohol extracts it in smaller quantity.

Absolute alcohol seems to extract a proteid, forming a deep yellow solution. A precipitate forms in it on dilution, not on heating; a precipitate is thrown down by nitric acid, soluble in excess, and also in dilute potash.

For quantitative purposes the albuminate was usually extracted by means of a simple condensing apparatus, which allowed the same alcohol to repeatedly wash a small quantity of flour (3-5 grams) placed in a funnel at the mouth of the flask in which the alcohol was kept boiling. Alcohol of about $60 \%$ was used ( $50 \mathrm{cc}$. water and $100 \mathrm{cc}$. methylated spirit), and was first allowed to drain through the flour into the flask in the cold. From this the condensed vapour passing over has at first a strength of over $90 \%$ alcohol, but as loss takes place the liquid in the flask becomes more watery, and the vapour represents a somewhat more dilute alcohol. At the end of from $3^{-5}$ hours it is found that all the alcohol-soluble proteid has been extracted. Fat and colouring-matter are 
present in the proteid as thus collected, and may be removed by ether: but the amounts given usually represent the crude albuminate (dried at $100^{\circ} \mathrm{C}$.). Three separate amounts of the flour used for gluten-estimation, each weighing 3 grams, gave albuminate representing $8.18 \%, 8.85 \%, 8.025 \%$ respectively; a fourth amount of 5 grams yielded $8.13 \%$ : average $8.29 \%$. A similar amount $(8.358 \%$ ) was obtained from flour which had been kept for some time at $100^{\circ} \mathrm{C}$.

In what form the albuminate exists in flour it is impossible to say, for no 'mother-substance' has yet been extracted; manifestly globulin is not the precursor, for it could then be extracted by salt-solution. Perhaps the suggestion ${ }^{39}$ of a 'mother-substance' in oats, antecedent to globulin, may here be applicable-a substance whence, according to the conditions of hydration, gluten or an albuminate may be formed.

\section{Relation between Gluten and the Albuminate.}

The question arises, what is the relation between the glian of gluten and the albuminate of flour? Are they identical?

Obviously they are alike, in the first place, as regards their solubility in alcohol: and just as the solubility of glian in this has been shown to vary, so that of the albuminate may be made to vary in the same way.

If a solution of albuminate in $75 \%$ alcohol be precipitated with water and allowed to stand for some time, the character of the albuminate left on evaporation is found to be changed: as already mentioned, it is less sticky, more tough and tenacious, and in physical properties resembles gluten. The residue obtained by the evaporation of an alcoholic solution may be treated with water with the same result. The substance thus obtained behaves towards alcohol in the same way as does gluten: it is no longer all soluble, and from the extract made with hot alcohol a precipitate is obtained on cooling. That is, zymom and myxon are formed from it; and a substance soluble in water (mucin) may be obtained in 
the same way as from the glian-solution from gluten. The derivates most characteristic of gluten are thus to be similarly obtained from the albuminate.

On the other hand, the alcohol-extract of gluten gives the reactions most characteristic of the albuminate, i. e. the zein reactions, showing that in each case the proteid has passed over into the same state, in which it is still soluble in alkalies, but refuses to dissolve in dilute acids. These reactions also show the connexions of the wheat-proteids with those of other cereals, the zein of maize (Gorham ${ }^{5}$, Ritthausen, Osborne), and the avenine of oats (Norton ${ }^{14}$, Osborne). By analogy we might name the albuminate the triticin of wheat, or glian, as it may similarly be obtained from gluten. The amount of gluten obtainable from flour is, however, greater than the amount of glian ever obtainable from the gluten of the same quantity of flour. This has already been explained as showing that some of the gluten, even in the moment of formation, is of the insoluble zymom form.

I have already tried to show that glian is ultimately a term co-extensive with gluten (zymom being a secondary product); and have now tried to prove the identity of glian with the albuminate, whence should follow the ultimate identification of the albuminate with gluten itself. An apparently serious discrepancy, however, shows itself in the amount of gluten, about $10.5 \%$, obtained from flour which yielded only $8.3 \%$ of the albuminate: the albuminate representing only $80 \%$ of the gluten, and this although no opportunity of zymom-formation has been permitted. This $20 \%$ however of the dry weight is not more than can be easily accounted for by the method of preparation of crude gluten: for it contains, as well as pure gluten, most of the fat of the flour and some starch and cellulose which cannot be removed by washing. The amount of fat present in flour is variously stated, and probably nearly all passes into the gluten. If we take the estimate of Peligot, who finds that the fat does not vary much from $1 \%$ for flour, we shall have $10 \%$ of gluten consisting of fat. On the other hand, the albuminate, extracted in the way employed, usually 
carried down a small amount of fat (? half), while the rest was left in the flour in the funnel: so that perhaps an excess of $5-6 \%$ of fat in gluten over that in the albuminate may be counted on. Von Bibra gives $5.85 \%$, Ritthausen $6 \%$, as the fat present in gluten. The residue of starch will vary with the nature of the gluten and the method of washing:-Ritthausen found $16 \%$ in one sample, in one case I found about $12 \%$. Add to these facts, the difficulty of thoroughly drying gluten in masses, even of the size in question (about I gram), and the probable retention of a small amount of water ; and the $20 \%$ difference between gluten and the albuminate will be fully accounted for.

Hence the $10.5 \%$ of crude gluten may be considered as thus constituted at the time of formation :-

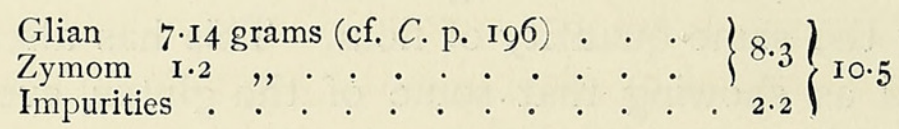

The glian and zymom together constitute what an earlier application of alcohol to the flour would have extracted as the $8 \cdot 3$ grams of albuminate.

This may seem but a rough and ready way of working; but, considering the rapidity with which these substances change during manipulation, and the difficulty in isolating them, it seems preferable to elaborate extractions with ether, and repeated solution in and reprecipitation from acid and alkaline solution. Even with all these at his command Ritthausen was only able to account for $70.3 \%$ of his crude gluten as the pure substance (the rest being fat, $6 \%$; starch, \&c., $16 \%$; loss, $7 \cdot 7 \%$. A confirmation of the approximate accuracy of their estimated composition is seen in the total proteid of the flour.

The total nitrogen in the flour used (as estimated by Mr. Manley, of the Magdalen College Laboratory) is $\mathrm{I} \cdot 761 \%$, representing probably not more than $10.566 \%$ proteid. (This is obtained by using 6 as the co-efficient : the large amount of nitrogen in the proteids would according to Ritthausen justify 
a still lower estimate.) This proteid may be thus accounted for :-

$\left.\begin{array}{ll}\text { Gluten (pure) } & \begin{array}{l}8 \cdot 3 \\ \text { Globulin } \\ \text { Proteose and proteid not accounted for }\end{array} \\ \text { I.I } 66\end{array}\right\}$ I0.566

The total nitrogen of $\mathrm{I} 00$ grams of flour, I.76I, may be similarly apportioned: Ritthausen gives $17.6 \% \mathrm{~N}$ in the wheat-globulin (albumin, R) ; Mr. Manley found $14.45 \% \mathrm{~N}$ in the crude gluten, dried at $100^{\circ} \mathrm{C}$ : :

$$
\left.\begin{array}{ll}
\text { Gluten }(10 \%) & \text { I.445 } \\
\text { Globulin ( } 1 \%) & \cdot 176 \\
\text { Proteose, \&c. } & .14
\end{array}\right\} \text { I.76 I }
$$

Obviously, the albuminate, forming $8.3 \%$ of the dry weight of flour, must, if not identical with the $8.3 \%$ of pure gluten, be largely coincident with it.

These figures seem to warrant the conclusion that the substance extracted by alcohol is the precursor of gluten : and it has been to some extent shown that the process of glutenformation is one of gradual hydration. The assumption that ferment-action is necessary to explain the process is precluded by the facts already mentioned: viz.:-

(I) Gluten is obtainable from flour which has been kept for some time at $100^{\circ} \mathrm{C}$;

(2) It is obtainable from such flour even when boiling water is employed to make the dough ;

(3) It is obtainable even at $0^{\circ} \mathrm{C}$.

Moreover if a ferment be necessary it must be as widely spread as the substance on which it acts: for not the smallest particle of flour apparently (unless indeed a starch-grain) can be moistened under the microscope without showing glutenformation: the same is seen in experiments ( $\mathrm{I}$ ) and (2) on gluten-formation (p. 190).

The origin of gluten from the globulins of flour seems disproved. The formation of gluten by washing as well with saltsolution as with water, would be impossible on that assumption (cf. also ( 1 ) and (2) under gluten-formation). Moreover, the inferences from the numerous analyses published by Jago ${ }^{34}$ 
by no means fit in with the globulin-theory. He estimated the amount of soluble albuminoids (i. e. globulin and proteose) and that of gluten from the most varied wheats, and there is no relation to be observed in his tabulated results : e. g.:-

\begin{tabular}{|c|c|c|c|c|c|}
\hline No. 9 & has & $.9 \%$ & sol. abuminoid & $8.09 \%$ & gluten \\
\hline 38 & ", & $.9 I$ & 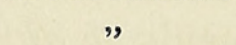 & 5.00 & " \\
\hline I6 & $"$ & 1.69 & $"$ & 6.25 & , \\
\hline 17 & ", & 1.69 & " & $8.2 I$ & $"$ \\
\hline $4^{2}$ & , & 2.03 & ", & 8.54 & ", \\
\hline $3^{2}$ & " & $2 \cdot 84$ & ", & $5 \cdot 54$ & ", \\
\hline
\end{tabular}

A proportion between gluten and albuminate is much more traceable, as the following figures show :-

$\left.\begin{array}{cccc}\text { Albuminate } & 8.3 \% & \text { gluten } & \text { r } 0.5 \% \\ , & 8.08 & , & 9.89 \\ , & 8.23 & , & 10.68 \\ , & 8.24 & , & \mathbf{1} 2.8 \\ , & 7.06 & , & 10.7\end{array}\right\}$

Moreover after removal of the albuminate by alcohol no gluten can be obtained from flour.

There must, then, be an extremely close connexion between gluten and the albuminate: so close as to justify us in saying that the substance which appears as the former as the result of hydration, appears as the latter on the exhaustion of flour by alcohol. As yet there is not much evidence as to the form in which it exists in flour. That it does not exist as gluten is clear-for in that case we should obtain from a given weight of flour the same amount of alcohol-soluble proteid, whether we at once extract the flour with the alcohol directly, or treat with alcohol the gluten obtained from the given weight of flour. The former amount is the larger, showing that the precursor of gluten is more soluble in alcohol than is gluten itself. And though the proteid extracted with alcohol from flour cannot be very far removed from the mother-substance of gluten (for it still has the power of gluten-formation), yet we cannot extract from it a proteid exactly in the state in which the gluten-precursor exists in flour. The residue which we obtain by evaporation is somewhat less soluble in acids than the mother-substance, which may be entirely dissolved in 
acids. The precipitate which we obtain by water resembles gluten; that obtained by means of ether resembles the residue on evaporation. No attempt to isolate the mother-substance by any other means has been successful. Dilute potash and hydrochloric acid alike remove it, but this is necessarily in the derived form of an alkali-albuminate or acid-albumin.

Therefore of the proteids as they exist in wheat we can as yet affirm nothing definitely: but we must now add to those already described as extracted (namely, myosin and proteose); another globulin, vitellin; and a fourth which readily passes into the hydrated state, the mother-substance of glutenhomologous with the zein of maize and Osborne's alcoholsoluble proteid of oats, in its solubility in alcohol, but distinguished from them by its physical properties dependent on its capacity for hydration.

\section{III.}

The endosperm of wheat comprises not only the central starch-containing cells which constitute the greater part of flour, but a peripheral layer of cells, rich in oil and containing numerous small aleuron-grains. The contents of these cells have long been known to be very rich in nitrogen, causing the percentage of nitrogen in bran to far exceed that in flour. An account of the proteids of wheat must therefore include some descriptions of the aleuron-cells and their contents.

There is no necessity to refer to the general literature of the subject of aleuron-grains : references to the earlier part are given fully by Pfeffer $^{5}$, and are brought down to a recent date by Lüdtke ${ }^{12}$. I need therefore only mention what has special reference to the aleuron-grains of the Gramineae.

Maschke ${ }^{3}$ (1859) recognised them and their localisation in the outer layers of rye, but gave no special account of them.

Sachs ${ }^{4}$ (1862) described the outer endosperm-layer of wheat as being rich in nitrogenous substances and containing oil.

Pfeffer ${ }^{5}$ gave some attention to them in his work on proteid-grains (1872), but it is somewhat difficult to know whether his remarks actually refer to what we now know 
as the aleuron-grains of the Gramineae. Thus he describes the grains as small and apparently without enclosures, but goes on to say that one can hardly speak of them as aleurongrains, the albuminous material simply drying to a granular mass between the starch-grains. Whilst recognising that the one or two outer layers of the endosperm in Grasses are free from the starch, he does not localise in them the grains described.

In the same year, however, Schenk, finding the not unnatural error of considering the aleuron-layer (Kleberzellen) as the seat of gluten (Kleber, used in the narrower sense) fairly widespread, clearly pointed out that the aleuron-cells do not contain gluten. The large amount of nitrogen to be found in bran seemed to confirm the popular view; but Schenk showed that this large percentage of nitrogen is due (1) to the presence of a nitrogenous substance not proteid in nature; (2) to the adherent parts of the endosperm, its outer layers, which are the parts richest in gluten. He first described in detail the reactions of the aleuron-layer. Millon's reagent, he found, did not affect the aleuron-cells; iodine stained them deeply, but as it also stained the testa and pericarp he did not consider this as any proof of the presence of proteid. Digestion with dilute hydrochloric acid, with alcohol, ether, or even with potash, he found to be without effect on the cells or their contents; whilst concentrated sulphuric acid gave a blackish colour. Hence he considered himself justified in supporting previous writers who had insisted on the low nutritive value of the nitrogen of bran. The difference between his negative results and those to be mentioned later as to the solubility of the contents of the aleuron-cells, is probably due to the comparative imperviousness of these cells when intact, the uninjured contents having probably never been reached by the reagent.

For some time no important addition was made to the knowledge of aleuron-grains. About 1878 , however, the aleuron-grains of many groups were described by Professor Vines $^{7}$, and their chemical nature investigated; but no 
account of the Gramineae is given, and their aleuron-grains were still practically unknown. Thus Godfrin (1884), describing the albumen of Zea Mays, states that the endospermcells contain starch only, the epidermis (presumably the aleuron-layer) being filled with a granular protoplasm.

Johanssen ${ }^{10}$ (1888) once more emphasised the fact that the starchy endosperm, and not the aleuron-layer, is the seat of gluten; a fact which, he tells us, was stated by Payen as early as 1846 . As for the peripheral cells of the endosperm (the aleuron-cells) - 'they contain tiny grains of an extremely slight resistance, nitrogenous in substance, which are embedded in a soft protoplasmic mass rich in fatty matter:' a description very different from that of Schenk. Of the more intimate structure of the grains no details are given.

Haberlandt ${ }^{11}$, however, in 1890 , found that the aleurongrains of Gramineae show no essential difference from those of other plants. In particular he describes those of Rye; they contain I-4 globoids in a ground-substance which is soluble in water.

Lüdtke ${ }^{12}$ in 1890 published a comparative account of the aleuron-grains of four groups of plants; and for the first time those of the Gramineae are adequately dealt with. His general conclusion is that Gramineae, Leguminosae, Umbelliferae and Euphorbiaceae form an ascending series as regards the developement of the aleuron-grains. He finds that in the Gramineae aleuron-grains, as known in other plants, have not yet been differentiated. Here they usually consist of a homogeneous central mass which should correspond to the globoid, and a surrounding membrane; of which Wheat affords a typical case. His observations as to their ready solubility agree with those of Johanssen rather than of Schenk. These grains, small and without enclosures, are in fact not real aleurongrains, but similar structures, occurring in a ground-substance with a fatty oil mixed in its molecules. In what the similarity consists, or how it may be stated in terms of their chemical composition, is not shown.

Groom ${ }^{14}$ in 1893 took up this part of the subject, and 
found that these grains contain the double phosphate of calcium and magnesium, characteristic of globoids. He therefore considered that the aleuron-grains of Gramineae are in every respect normal, consisting of a small peripheral layer of proteid, and an exceptionally large globoid. Of the proteid substance he does not treat, beyond mentioning the observation that it dissolves in potash, setting free the globoid.

The following work was undertaken in 1893, at the suggestion of Professor Vines, in order to try to complete our knowledge of the aleuron-grains of the Gramineae with some account of their proteid constituents. It will be seen that my observations chiefly agree with those of Lüdtke, in part combining his results with those of Mr. Groom.

\section{The Aleiron-Layer of Wheat.}

The constitution of the aleuron-layer of the Gramineae has been frequently described. Whilst in most starch-containing seeds starch and aleuron-grains occur together throughout the endosperm, the aleuron-grains are here confined to its specialised outer layers, starch to its central mass.

In Wheat the aleuron-layer is in most places but one cell thick, and is protected externally by a strongly cuticularised layer of the testa. The continuity of protoplasm from cell to cell may easily be seen in a thickish section without other preparation than careful staining in Hoffmann's blue and mounting in glycerine. On treating a section with absolute alcohol, and then with concentrated sulphuric acid, a persistent pink protoplasmic network shows continuity between the aleuron-layer and the rest of the endosperm. The immediately underlying cells are specially rich in proteid matter (gluten); their starch-grains are somewhat larger than the aleuron-grains and are fairly regular in size. Most of the endosperm-cells, however, contain large circular flattened starch-grains, the interstices between which are so densely packed with minute, often angular starch-grains, that the proportion of gluten is small. 
The aleuron-layer comes into close relationship with the embryo in two ways: (I) Its cells are continued over the external surface of the edge of the scutellum where it reaches the convex side of the grain; and here the aleuron-cells of the two seem continuous. This fact is the more noticeable because the cells of the scutellum bordering on the endosperm proper are glandular, whilst those forming its boundary towards the plumule are cuticularised. The aleuron-layer seems also to be continued over the rest of the embryo externally. (2) Beneath the well-marked furrow of the grain of Wheat the aleuron-cells pass inwards, the layer from one side meeting that from the other, both then sinking for some way into the endosperm proper. Thus, towards the base of the seed, they come into direct contact with the glandular face of the scutellum. Hence, the 'ringing' experiments in which it is attempted to destroy the connexion between embryo and aleuron-layer by an incision round the margin of the scutellum are not decisive, the second means of possible communication remaining intact.

The Aleuron-Cells. - Each cell of the aleuron-layer is polygonal in outline in surface view, with walls normal to the surface of the seed. Its protoplasm is continuous with that of adjoining aleuron-cells and that of the underlying endosperm; it encloses a large nucleus, and forms a firm close network embracing the aleuron-grains. Much oil is present, and perhaps some carbohydrate; this seems the explanation of the effect of the addition of concentrated sulphuric acidthe protoplasm being immediately fixed and assuming a deep rosy tint. (Cf. the black colour observed by Schenk on addition of strong sulphuric acid.)

The Aleuron-Grains.-Each aleuron-grain, as observed on the first addition of water or glycerine, or in oil or almost any mounting medium, is seen to be a spherical or somewhat angular body. It is seen also to consist of a central core surrounded by an outer layer. The core is a refracting body, more or less soluble in water, salt-solutions, dilute acids, and alkalies; it does not readily stain. The outer layer, on the 
contrary, stains with iodine, haematoxylin, and aniline-stains, and does not dissolve in any of the above-mentioned reagents. Therefore, as compared with an ordinary aleurongrain, the peripheral layer corresponds to the membrane, whilst the core unites in itself the characters of globoid and proteid ground-substance.

The degree of the solubility of the core differs considerably with the reagent employed, and various characteristic reactions occur. For observation I used sections cut dry, and at first treated them with ether to remove oil ; the presence of oil, however, does not with most reagents interfere with one's observations after a little experience. My method was therefore simply to lay the section of the grain of Wheat on a slide under a cover-glass; to then run in a drop of absolute alcohol, in order to get a particular cell or aleurongrain under observation, under the microscope; and, lastly, to irrigate the section with the reagent in question. In some cases, where solution for more than a few hours was necessary, the sections were kept in the reagent in a watch-glass. On running in the more slowly acting reagents the same results could be observed by using perfectly dry sections.

Water.-The core at once appears more distinct, and within five or ten minutes seems to be dissolving from the outside; dissolution may also proceed from the centre or may be irregular. The process is slow, and may not be completed till after one or two days, especially in those cells of the aleuron-layer which are still intact. Dissolution is assisted by slightly heating the slide. Finally only the peripheral part is left, a hollow sphere-this is quite unattacked by water even after six days.

Salt-Solution $(\mathrm{NaCl} 10 \%)$.- At first this acts more energetically than water, and in free-lying grains dissolution may be completed in less than an hour. Solution usually takes place in much the same way as in water; sometimes the core breaks up into three or four smaller spheres. Ultimately the process is less rapid, owing probably to the greater difficulty with which the solvent penetrates the protoplasmic 
network. The membrane persists, sometimes in a contracted form, which can, however, be made to resume its former dimensions by the use of caustic potash. A $20 \%$ salt-solution at first attacks the grains more readily, but it cannot cause complete dissolution; whilst in a weaker solution $(1-5 \%)$ the process is regular and frequently takes place from within, when the core itself appears as a hollow sphere. Statements as to the insolubility of these aleuron-grains in water and salt-solutions seem to be due to the persistence of the peripheral layer or membrane, which may be mistaken for the intact grain. Confirmation of their having passed into solution is afforded by the fact that a drop of the water or salt-solution employed gave a calcium reaction, forming insoluble crystals of calcium oxalate when evaporated on a slide with an ammoniacal solution of ammonium oxalate and chloride. I did not think it necessary to test similarly in each case for magnesium and phosphates.

In Alcohol $(50 \%)$ the core of the aleuron-grain seems to dissolve from within, somewhat more rapidly than in water. The effect of absolute alcohol ( 2 months) is to render it insoluble in water and salt-solution, and only soluble in potash on standing for twelve hours.

Ammonium chloride dissolves the core at once from without, and the membrane also rapidly dissolves, though it is sometimes the last thing to disappear.

Sodium phosphate $\left(\mathrm{Na}_{2} \mathrm{HPO}_{4}\right)$ dissolves both core and membrane, thus showing that the former is not of the nature of a crystalloid, this being left untouched by this reagent (Lüdtke ${ }^{12}$ ). If this salt is added in ammoniacal solution of ammonium chloride, crystals of ammonium and magnesium phosphate prove the presence of magnesium.

Caustic potash $(\mathrm{I} \%)$ acts violently on the cell-protoplasm, which swells up and sets free the grains. The core slowly dissolves, usually from without; a small central mass may often persist for some time, but it finally disappears. The membrane becomes transparent, but does not dissolve, as is evident after addition of water or on neutralisation, especially. 
on staining with iodine. Even after five days in dilute potash the membrane persists; it may, however, be dissolved by a concentrated solution.

It is this comparatively easy solution in caustic potash (as well as in water and salt-solutions) which distinguishes the core of the aleuron-grains of Wheat (and probably of the Gramineae in general) from the globoids of other aleurongrains, and which probably indicates the presence of some proteid body.

Other alkaline solutions, e.g. sodium and ammonium carbonates, give similar results; so also does calcium hydrate if a concentrated solution is used.

Acetic acid $\left(\mathrm{I}^{\circ} \mathrm{)}\right.$ ) gradually dissolves the core from within, and finally the membrane also.

Hydrochloric acid (whether $1 \%$ or $10 \%$ ) immediately dissolves both membrane and core.

Sulphuric acid $(1 \%$ or $10 \%)$ immediately dissolves the whole grain. The concentrated acid dissolves the core first, then the membrane; though it occasionally appears to fix the latter, which then persists for some time. The last remnant of the core, too, frequently persists as a minute dark spot, indicating perhaps the presence of oil or a carbohydrate, or the fixation of the proteid constituent of the core by the strong acid. The simultaneous formation of monoclinic crystals $\left(\mathrm{CaSO}_{4}\right)$ in the cells and their immediate neighbourhood shows the presence of calcium: this may be confirmed by adding to a dry section a solution of ammonium oxalate and chloride, in ammonia, when the aleuron-grains are seen to dissolve and octahedral crystals to appear, which are insoluble in acetic acid and are, therefore, presumably of calcium oxalate. Especially. when the section has been previously treated with absolute alcohol, the characteristic pink proteid reaction already mentioned may be observed with concentrated sulphuric acid.

Nitric acid (concentrated) does not precipitate the proteids, but dissolves the grains at once, the cytoplasm a few seconds later. 


\section{O'Brien.-The Proteids of Wheat.}

Tannic acid (conc.), osmic (10\%) and picric (conc.) acids dissolve the core, leaving the membrane.

The Proteids of the Aleuron-Layer.-The colour-reactions and staining properties of the membrane of the aleuron-grain show its proteid nature. But it is improbable that the large amount of nitrogenous matter shown by analysis to occur in bran is confined to the peripheral parts of the aleuron-grains and the protoplasmic network. A partially proteid composition of the core of the aleuron-grain has been suggested by its solubility, as already mentioned; it is further supported by the composition and behaviour of an extract made from bran by water-it being remembered that water dissolves the core and not the membrane, and that it leaves the greater part, if not the whole, of the cytoplasm untouched.

The watery extract of bran seems to contain two proteids, giving Millon's, Piotrowski's, and the xanthoproteic reactions : (I) a coagulable proteid, probably a globulin dissolved in presence of the mineral salts; (2) a proteose which may be precipitated by concentrated salt-solutions from the filtrate from (I) after its coagulation by heat. Evaporated to dryness, the extract yields a gelatinous substance, yellow in bulk, and semi-transparent, separating out in part in small round spheres. These spheres are interesting as being, I believe, artificial aleuron-grains ; they give all the reactions of those embedded in the cell-protoplasm. It may be specially noted that their outer layer partially resembles the membrane of the natural aleuron-grains, dissolving in water and even in potash only after some hours' treatment.

Bran extracted with alcohol $(50 \%)$ yields a solution containing proteid, which agrees in its reactions with the extract made from flour.

Examination of the flakes of bran after treatment with water shows the core of the grains to have dissolved; but the process is slow in unbroken cells, and the small amount of matter in solution obtained from bran by short treatment with water depends on the difficulty with which this penetrates to the grains. This has also been proved by Jago's results, the 
amount of soluble matter yielded by bran depending on the fineness to which it is ground. Thus the nutritive value of bread containing bran=must depend, not on the absolute amount of nitrogenous matter present, but on the degree in which it is accessible to the action of liquids. For though the nitrogenous matter is not ordinarily available for nutrition, there is no reason to suppose that it is, in its nature, useless for this purpose, as has been urged (Poggiale ${ }^{2}$ and others).

The Aleuron-Layer during Germination. - After being soaked in water for two days, wheat was sown, and later, examined at intervals. After one day the grains in the aleuron-layer did not seem to be affected, nor did those on the convex side of the grain after four days; whilst those from the grooved face showed greater solubility than the former, and in some cases seemed already dissolving from within.

After eight days, when the plumule is above ground and long adventitious roots are present, the aleuron-grains still persist ; but by the nineteenth only the membranes of the grains persist, and no mineral $(\mathrm{Ca})$ is present in the aleuron-cells. At this time only a small part of the endosperm seems to have been used, but the starch-grains immediately under the aleuronlayer are much corroded.

Function of the Aleuron-Layer.-(I) The aleuron-layer is frequently considered chiefly as a part of the reserve store for the embryo.

(2) A conducting function (of diastase from the embryo) has also been suggested.

(3) It is usually considered to be concerned in the diastatic solution of starch (Johanssen ${ }^{10}$ ), whether by actual secretion of diastase (Haberlandt ${ }^{11}$, \&c.) or, as just mentioned, by conduction. This is also the general opinion among bakers, the aleuron-layer of bran (cerealin-cells) being supposed to exert a diastatic action on flour, shown in 'softening' of the dough 9 .

(4) The presence of a gluten-transforming ferment is suggested by Balland ${ }^{8}$.

The diastatic function of the aleuron-layer has been denied 
by Brown and Morris ${ }^{13}$, but their experiments do not seem exclusive of the possibility of some such function of the aleuron-layer, accessory to the scutellar epithelium. For, as already shown, there is no necessity for a stimulus from the embryo (if such be needed) to traverse the lifeless endosperm to reach the aleuron-layer, since the two are in contact below the furrow, towards the base of the grain. Nor does a decreased diastatic activity of the aleuron-layer after the embryo is detached necessarily prove that the enzyme comes from the embryo. Again, though in Barley the course of starch-dissolution may be independent of the aleuron-layer, this does not seem to be the case in Wheat. For while towards the tip of a germinating grain (four days) the starchgrains in the centre of the endosperm are intact, those in the cells immediately underlying the aleuron-layer have already begun to undergo dissolution, showing the characteristic radial pittings-and this both on the dorsal and the central face of the seed. But I have given no special attention to the question of the function of the aleuron-layer.

However, it rests with those who consider the aleuron-layer merely as a specialised reserve store to explain why it consists of apparently living cells with a large and perfect nucleus, whilst the rest of the endosperm-cells, as shown by Brown and Morris, are lifeless. In any case, it seems to me that cultivated grain, with a much larger proportion of starchy endosperm than that naturally present in the Gramineae, is hardly the best material from which to form an opinion as to the normal functions of the aleuron-layer.

\section{The Aleuron-Layer of other Cereals.}

Oats.-The aleuron-layer is one cell thick as in Wheat; and the grains show much the same degree of solubility.

Zea Mays.-The aleuron-grains are smaller and less regular than those of Wheat. They appear to contain a small globoid, or more than one, which is surrounded by a peripheral mass of proteid too thick to be considered a membrane, and which 
is soluble in $1 \%$ potash. They, therefore, nearly resemble ordinary aleuron-grains; but the enclosure being soluble in dilute potash, and in salt-solution on standing, is not a true globoid, but resembles the core of the aleuron-grain of Wheat.

Barley is exceptional in having an aleuron-layer several cells in thickness. The aleuron-grains resemble those of Wheat in form and behaviour; but the membrane is more soluble in potash, and the core less sharply defined.

Rye.-The aleuron-grains show considerable variation in size, and resemble those of $Z e a$ in the large proportion of proteid present. Haberlandt ${ }^{11}$ mentions the occurrence of as many as four globoids.

From the preceding observations it would appear that the aleuron-grains of the Gramineae do not present that degree of differentiation in which the mineral matters are sharply separated off, as a globoid, from the proteid constituents of the grain. Only the membrane, consisting usually of coagulated or at least of very insoluble proteid, is here differentiated. Within this, the substance of the aleuron-grain contains, as has been proved by Mr. Groom, the phosphates of magnesium and calcium, like the globoids of typical aleuron-grains. But that it likewise consists of some nitrogenous substance seems the conclusion separately drawn by Johanssen and Lüdtke from their different observations, and the present results confirm this view. Hence it seems to me that the aleuron-grains of Wheat, within a membrane of coagulated proteid, contain a sphere of a homogeneous substance combining the proteid (globulin and proteose) and mineral matters, differentiated in other plants into groundsubstance and globoid. Thus the various apparently conflicting theories as to the aleuron-grains of the Gramineae may be harmonised.

Finally, I wish to express my indebtedness to Professor Vines for the suggestions he has made, and my thanks for the kind interest he has taken in my work.

BOTANICAL LABORATORY, OXFORD, March, I 895 . 
Since writing the foregoing pages, my attention has been drawn by Prof. Green's article in 'Science Progress' for March, I 895, to some work on the proteids of wheat (Amer. Chem. Journ., I893; Journ. of the Amer. Chem. Soc., I894) by Messrs. Osborne and Voorhees, with which I was unacquainted. This work to some extent covers the same ground as my own, but our results are not altogether concordant.

I find, however, that I am in agreement with these authors in my conclusions as to the ferment-theory of gluten-formation, and as to the supposed origin of gluten from the globulin of flour.

Apart from gluten, they find three proteids in flour which seem to correspond to those which I have described under somewhat different names, as indicated in the following table:

$$
\begin{aligned}
& \text { Globulin [edestin] } \cdot 6-\cdot 7 \%, \quad \text { I } \% \text { corresponding to Vitellin Globulin } \\
& \text { Albumin [leucosin] } \cdot 3-4 \% \text { I } \% \text {, }, \text { Myosin }\} \text { I } \% \text {. } \\
& \text { Proteose . }
\end{aligned}
$$

Leucosin is described as an albumin with the exceptional characters (I) of being precipitated on saturation with ammonium or magnesium sulphates, and (2) of coagulating at the low temperature of $52^{\circ} \mathrm{C}$.; whereas the conclusion at which I have arrived is that this proteid is a glabulin of the myosinclass.

These authors describe the proteids of gluten as follows :

$$
\begin{aligned}
& \text { Sol. in dilute alcohol } \\
& \# \text { only in dilute acids or alkalies : }
\end{aligned} \quad \begin{aligned}
& \text { Gliadin } 4 \% \\
& \text { Glutenin } 4 \%
\end{aligned}
$$

They thus return to the view of Taddei, and in part to his terminology. Whilst they reject his term 'zymom,' as implying ferment-action, they retain 'gliadin' for the substance which I have termed 'glian' on account of the varying sense in which the term 'gliadin' has been used by different writers, having been applied sometimes to the whole, sometimes to a part only, of the alcohol-soluble constituents of gluten. Moreover, the view which they adopt as to the mutual relation of these two substances differs essentially from that which my observations seem to suggest. They 
consider, namely, that the constituents of gluten (gliadin and glutenin) exist in flour in the same proportions as in gluten; and that, therefore, gluten may be said to exist as such in flour. I find, on the contrary, that these substances may be extracted from gluten in varying proportions, according to the method employed; this suggests that the one may be derived from the other; and it is probably the less soluble substance (zymom) that is derived from the more soluble (glian): hence the alcohol-soluble substance (glian) is ultimately co-extensive with gluten. I was, in fact, able to extract about $8 \%$ of this substance from flour; but whilst I must admit that the method of extraction was likely to bring with the albuminate or glian a certain proportion of other substances, it seems to be highly improbable that the quantity of these impurities could be such as to reduce the amount of pure glian to the $4 \%$ indicated by Osborne and Voorhees. Although in most cases the larger quantities of flour with which they worked would enhance the value of their results as compared with mine obtained from small quantities, yet in this particular instance the repeated washing of the smaller quantity of flour may have been more thorough than could be possible with a larger quantity.

The facts seem to me to indicate the existence of one mothersubstance in flour, which readily undergoes hydration, giving rise to gluten. For we can, as it were, intercept the hydration at any point, and obtain, consequently, a larger or a smaller amount of alcohol-soluble substance (glian), by extracting gluten with alcohol at an earlier or later stage in its progress to almost complete insolubility. Moreover, it seems almost impossible to completely extract from flour the whole of the alcohol-soluble proteid with $75 \%$ alcohol in the cold; this again is suggestive of a gradual hydration of a mothersubstance. 


\section{BIBLIOGRAPHY.}

\section{I and II.}

1. Beccari (quoted by Ritthausen): Commen. Bonon. I. I, I 22.

2. Cadet (quoted by Einhof): Scherer's Jahrb., Bd. ix. S. 569 .

3a. Einhof (1805): Gehlen's J. der Chemie, Bd. iv. S. 315; Analyse der Erdäpfel.

36. Einhof (1805) : Ibid. Bd. v. S. I31, Analyse des Roggens; S. 62, der Gerste; S. II 5, der Erbsen u. der reifen Saubohnen.

4. Taddei (1819): Summary in Schweigger's J. f. Chem. und Physik, xxix. I820; also in Berz. Jahresb. d. Ch. i. 1822.

5. Gorham (1822): Berz. Jahresb. ii. S. I24; Zeïne.

6. Berzelius (1828): Jahresb. vii. S. 23I ; Pflanzenleim und Pflanzeneiweiss.

7. De Saussure (1833): Summary in Jahrb. d. Chem. und Physik, S. I88; Bildung des Zuckers beim Keimen des Waitzens.

8. Boussingault (I837): Ann. de Ch. et de Physique, lxv; La quantité de gluten, \&c.

9 a. Mulder (1839): J. f. prakt. Ch.; Die Zusammensetzung einiger thierischen Substanzen.

9b. Mulder (I840): Summary in Berz. Jahresb. d. Ch. xix; Bestandtheile des Bluts.

10. Berzelius (1840): Jahresb. xix. S. 637 ; Bestandtheile des Bluts.

11. Liebig (1840): Ann. de Ch. et de Pharm. xxxix. S. I26; Die stickstoffhaltigen Nahrungsmittel des Pflanzenreichs.

12. Denis (I $84^{\circ}$, quoted by Scherer) : J. de Ch.-Méd. Sc. Sér. iv.

13. Dumas et Cahours (1842): Ann. de Ch. et de Physique, Sér. iii. No. 6 ; Les matières azotées neutres de l'organisation.

14. Norton (I848): Am. J. of Sci. Ser. II, 5 ; Protein Bodies of Peas, \&c.

15. Peligot ( $\left.185^{\circ}\right)$ : Ann. de Ch. et de Pharm. Sér. III, xxix; Sur la composition du blé.

16 a. Hartig (I 855$)$ : Bot. Zeit. S. 88I ; Ueber das Klebermehl.

16b. Hartig $\left(185^{6}\right)$ : Ibid. S. 257 , Weitere Mittheilungen das Klebermehl betreffend.

17. Denis (1859) (quoted by Hoppe-Seyler): Mémoire sur le Sang, Paris.

18. Von Bibra (I860) (quoted by Ritthausen): Die Getreidearten und das Brod, Nürnberg.

19. Günsberg (I862): J. f. prakt. Ch. Ixxxv. S. 2I3; Im Wasser lösliche Bestandtheile des Klebers.

20. Kühne (I864): Das Protoplasma, \&c., Leipzig.

21a. Hoppe-Seyler (I865): Handbuch d. phys. und path. chem. Analyse, 2te Aufl.

216 . Hoppe-Seyler (1 865-70) : Med.-chem. Untersuchungen。

21 c. Hoppe-Seyler (I870): Handbuch, 3te Aufl.

22. Ritthausen (1872): Die Eiweisskörper der Getreidearten, Bonn.

23. Weyl (1877) : Zeitschr. f. Phys. Chem. i; Die thierischen und pflanzlichen Eiweisskörper.

24. Ritthausen (1877): Pflüger's Arch. f. Phys. xv. S. 269; Die Eiweisskörper der Pflanzensamen. 
25. Barbieri (1878): J. f. prakt. Chem. xviii. S. I08; Eiweisssubstanz der Kürbissamen.

$26 a$. Vines (1878) : Proc. Roy. Soc. xxviii. p. 218.

26 b. Vines (I880): Ibid. xxx. p. 387 .

26 c. Vines (1880): Ibid. xxxi. p. 62 ; Chem. Composition of Aleurone Grains.

27. Ritthausen (1880) : Pflüger's Arch. S. 81 ; Die Eiweisskörper der Oelsamen.

28. Weyl und Bischoff (I880): Ber, deutsch. Chem. Ges. S. 367; Ueber den Kleber.

29. Bénard et Girardin (188I): J. de Pharm. et de Chim. Sér. 5. T. iv. p. I 27 ; Le dosage du gluten.

30. Hoppe-Seyler (I 88I) : Physiologische Chemie, Berlin.

31. Vines (I882) : J. of Physiol. iii ; Proteid substances in Seeds.

32 a. Balland (I883): J. de Pharm. et de Chim. Sér. 5. T. viii. p. 347 ; Mémoire sur les farines.

32 b. Balland (1884): Ibid. T. x. p. 266; Second Mémoire.

33. Martin (I885): J. of Phys. vi. p. $33^{6}$; Papain.

34. Jago (I886): Chemistry of Wheat, \&c., Brighton.

35. Martin (1886) : Brit. Med. J. ii. p. I04; Gluten and Proteids of Flour.

36. Martin (1887): J. of Physiol. viii ; Vegetable Globulins.

37. Kjeldahl (quoted by Johanssen): Compte-rendu de Carlsberg, T. i.

38. Johanssen (1888) : Ibid. vol. ii. livr. 5; Sur le gluten, \&c.

39 a. Osborne (1890): Am. Chem. J. xiv. 3 ; Proteids of the Oat Kernel.

39 b. Osborne: Ibid. xiv. 8 ; Crystallised Proteids.

41. Chittenden and Osborne (I89I-2): Am. Chem. J. ; Proteids of Maize Kernel.

42. Balland (1893): J. de Pharm. et de Ch., Sér. 5. xxvii. p. $25^{8}$; Sur la préexistence du gluten dans le blé.

See also Haliburton: Chemical Physiology and Pathology, chap. x. : Article, 'Proteids,' in Watts' Dict. of Chem. (I 894).

Sheridan Lea (1892): Chemical Basis of the Animal Body.

Hoppe-Seyler (1 893) : Handbuch der phys. und path. chem. Analyse, Berlin.

\section{III.}

1. Mège-Mouriès (I 853$)$ : quoted by Schenk 6 .

2. Poggiale (1853): quoted by Schenk 6 .

3. Maschke (1859): Bot. Ztg.; Die Kleberbläschen in Bertholletia, \&c.

4. Sachs (I862): Bot. Ztg.; Zur Keimungsgeschichte der Gräser.

5. Pfeffer $\left(187_{2}\right)$ : Pringsheim's Jahrb. viii.; Proteinkörner.

6. Schenk $\left(18 \gamma^{2}\right)$ : Untersuchungen, Wien: Ueb. die Vertheilung des Klebers.

7. Vines $(1878)$ : see I. 26,31 .

8. Balland $\left(1883^{-5}\right)$ : see I. 32 .

9. Jago (I886) : see I. 34.

10. Johanssen (I888): see I. 34.

11. Haberlandt (I890): Ber. deutsch. Bot. Ges. viii. ; Die Kleberschicht des GrasEndosperms, \&c.

12. Lüdtke (I 890): Pringsheim's Jahrb. xxi.; Die Aleuronkörner.

13. Brown \& Morris (1890): J. of Chem. Soc.; Germination of some of the Gramineae.

14. Groom (1893): Ann. of Botany, vii.; The Aleurone-Layer of the Seeds of Grasses. 


\section{$2 \mathrm{BHL}$ Biodiversity Heritage Library}

O'Brien, M. 1895. "The proteids of wheat." Annals of botany 9, 171-226. https://doi.org/10.1093/oxfordjournals.aob.a090736.

View This Item Online: https://www.biodiversitylibrary.org/item/233478

DOI: https://doi.org/10.1093/oxfordjournals.aob.a090736

Permalink: https://www.biodiversitylibrary.org/partpdf/318376

\section{Holding Institution}

Smithsonian Libraries

\section{Sponsored by}

Biodiversity Heritage Library

\section{Copyright \& Reuse}

Copyright Status: Not in copyright. The BHL knows of no copyright restrictions on this item.

This document was created from content at the Biodiversity Heritage Library, the world's largest open access digital library for biodiversity literature and archives. Visit BHL at https://www.biodiversitylibrary.org. 